\title{
6. Examination of the Case Material and the Conclusions Drawn from It
}

Makek M: Clinical Pathology of Fibro-Osteo-Cemental Lesions in the Cranio-Facial and Jaw Bones. Basel, Karger, 1983, pp 53-104

\section{WHO Classification Applied}

All the biopsy material analzyed at the Institute for

Pathology of the Zürich University Hospital between

1950 and 1980 was systematically reviewed so that all the cases on file which might possibly be fibroosteo- cemental lesions could be compiled for more detailed evaluation [Makek, 1982]. Genuine odontogenic tu- mors, obvious cases of osteomyelitic alterations, cysts, and epithelial benign and malignant tumors were all eliminated at the outset.

Of the lesions still included, 365 were centrally located. They were all subjected to microscopic examination before being definitively classified. Those which microscopic examination clearly showed not to be fibro-osteo-cementallesions were then eliminated. Among the specimens thus excluded were cases of such entities as odontogenic fibroma with islands of epithelium, osteoma and exostosis, Paget's disease, giant cell granuloma, myxoma, neurofibroma, hyper-cementosis, cherubism and periostitis ossificans. In this way, 107 ofthe 365 centrally located lesions were finally retained. New representative specimens of each 
Since the biopsy material used for the present study covers the last 30 years, whereas the relevant WHO classification [Pindborg and Kramer, 1971] shown in table I officially came into force only in 1971, it soon became apparent that the material used

here would have to be reevaluated in the light of the criteria presented in the WHO classification. When re- examined in the light of the WHO classifications, the 107 applicable cases were diagnosed as_shown in table VII. The most remarkable result ofthis exercise was the fact that the largest group ofall, comprising 27 cases, were lesions which could not be defined in terms of the WHO classification (table VIII).

Some difficulty was also experienced in classifying

lesions in the ossifying fibroma group (table IX) and the cementifying fibroma group (table X). The intro- duction of a third group often encountered in the liter-

Table VII. Results obtained when the 107 cen-trally located bone lesions were reevaluated in the light of the current WHO classification

of these cases were prepared and each specimen was subjected to hematoxylin and eosin, van Gieson and alcian blue-PAS staining. A number ofthe specimens also underwent further special staining tests, such as Goldner's and Giemsa's, so that the ossification pro- cesses involved could be considered in greater detail.

The thorough microscopic examination to which each specimen was subjected was complemented by a detailed review of all the clinical and radiological material pertaining to each case. In 20 of 107 cases of centrally located lesions, the biopsy material available had in fact been excised abroad and had then been sent to the Director ofthe Institute at the time, Professor E. Vehlinger, for hisexpert opinion. In a number ofthese cases, the clinical and radiological material was not available in its entirety. 
Unclassifiable lesions, of which:

b) poorly defined, and of doubtful

reparative origin 16

2 Periapical cemental dysplasia

25

3 Fibrous dysplasia 17

4 Ossifying fibroma 13

5 Cementifying fibroma 14

6 Cemento-ossifying fibroma 10

7 Cementoblastoma

Total 107

Table VIII. Statistkai breakdown for the 27 unclassifiable lesions

a) Tumorous, well-defined lesions $(n=11)$ 
Table IX. Ossifying fibroma (13 cases)

\section{Sexdistribution Loca/ization}

Fernales $8 \quad$ Maxilla 6

Sex distribution

Fernales 4

Males 7 


\section{Loca/ization Maxilla Mandible}

\section{Paranasal cavities}


Males

5

Mandible

6

3

Orbit

4

Age distribution

4

Age distribution

\section{Decade}

n 
3 
$31-40$

5 
3 
Table X. Cementifying fibrorna (14 cases)

b) Poorly defined and of doubtful reparative origin $(n=16)$ 
Fernales $8 \quad$ Maxilla 3

Sex distribution

Fernales 10

Males 6

Age distribution 
Loca/ization Maxilla Mandible Orbit 


$\begin{array}{lll}\text { Males } & 6 & \text { Mandible } 2 \\ \text { II } & \text { Paranasal cavity } \\ 4 & \text { region } 5\end{array}$

Frontal region

Temporal region I

Parietal region 2

Age distribution

Decade

$11-20$

$21-30$

$31--40$

$41-50$

Decade

0-10

$11-20 \quad 21-30 \quad 31--40$

$41-50$

n

6

4

5

I

n

2

3

$5 \quad 2$

2 
ature, terrned 'cernento-ossifying fibroma' did not make it possible to overcorne all the difficulties thus encountered (table $\mathrm{XI}$ ). It also ernerged that periapical cernental dysplasia (table XII) was the only lesion which could be diagnosed with cornplete certainty on the basis of clinical and radiological examinations alone. These would therefore be sufficient to distin- guish it frorn cementifying fibroma, although cernen- tifying fibroma itself can only be diagnosed with com- plete certainty if clinical and radiological findings are supported by a histological examination. Further-more, although periapical cemental dysplasia can be diagnosed with cornplete certainty on the basis of clin- ical and radiological exarninations alone, the histolog- ical findings produced would not, in themselves, be sufficient to diagnose the condition with certainty.

A consideration of those cases which the WHO classification showed to be fibrous dysplasia uncov- 
- ered the following discrepancy: although the relevant histological criteria showed that this condition, which affects children and adolescents exclusively, occurred in 8 cases where the patientwas aged less than 20 , they also produced a further 5 cases where the patient was aged between 40 and 60 (table XIII).

The fernale:male distribution ratio was 10:7, which corresponds with the findings of Dehner [1973] and Eversole et al. [1972]. The lesion also showed a rnarked predilection for the rnaxilla, on which point the present study also concurs with the authors just cited.

Of all the lesions considered there was only I case

of cernentoblastorna: the condition occurred in a 20 -year-old male, and neither its radiological nor its his- tological diagnosis caused any problerns.

There were a total of 25 cases of periapical cernen- tal dysplasia (table XII), 20 of which occurred in female patients. In only 3 cases was the lesion located

Table XI. Cemento-ossifying fibroma (10 cases) Table XIII. Fibrous dysplasia (17 cases)

Sexdistribution Localization Sexdistribution Localization

Fernales

4

Maxilla

2

Fernales

10

Maxilla

9

Males

6

Mandible

8

Males

7

Mandible 
Orbit

3

Paranasal cavities

Age distribution 
Age distribution

\section{Decade}

n 
$0-10$

2 
2 
2 
2 
$41-50$

2 
$11-20 \quad 21-30 \quad 31-40 \quad 41-50 \quad 51-60$

3

2

2

4

Table XII. Periapical cemental dysplasia (25

cases) 
ity) of the lesions assigned to this last group occurred in patients aged between 10 and 30 , and that they were most frequently located in the maxilla. Of the well-

\section{Sexdistribution}

Fernales 20

Males 5

Age distribution 
Localization

Maxilla

Mandible 
not result in any par- ticular homogeneity between the lesions in either of

— the groups thus created.

\section{Decade}

n 
Every single one ofthese unclassifiable lesions was characterized by the fact that there were fundamental differences between the diagnoses returned by sur-geons and radiologists on the one hand and those returned by histopathologists on the other. Examples

of this include radiological and clinical diagnoses of

in the maxilla. Patients aged between 30 and 49 were the most frequently affected. These findings coincide with the observations made by Stafne [1943] and Zegarelli et al. [1964] on all counts.

As has been mentioned, the case material used for the present study contained lesions which could not be positively diagnosedas definitely belanging to any one of the entity groups described in the WHO classi-fication. To facilitate presentation, they have been divided into two categories: well-defined tumor-like lesions and poorly defined lesions of questionable reparative origin. There were repeated instances of lesions where, although intense bone remodelling oc-curred, the newly formed bone had no apparent func- tional structure. It was in order to cater for these lesions that the second subcategory (poorly defined lesions of questionable reparative origin) was created. Ofparticular interest is the fact that 10 (i.e. the major- 
- fibrous dysplasia in patients of advanced age, Paget's disease in young patients and fibrous dysplasia appar- ently histologically characterized by osteomyelitic changes. There were further instances of diverging radiological and histopathological diagnoses where conditions which were classified radiologically as dif- fuse areas of radiodensity were histopathologically diagnosed as ossifying fibroma or osteofibroma. His- topathological examinations showed these processes to be tumoraus and one would therefore have expected them to be weil defined on X-ray. Furthermore, when they were being surgically removed, it should have been possible to shell them out, though this was not in fact the case. It should also be noted that some lesions which were clinically and radiologically diagnosed as tumors were quite often classified histologically as fibrous dysplasia or isolated dystrophy of the jaw, neither ofwhich are tumorous processes.

Fig. 53. Cross-section giving a generat histological view. The normal bone structure has dis- appeared and broad lamellae of bone tissue have been formed, some of which are grouped to- gether into parallel curves. HE.

$5.5 \times$. 
Fig. 54. Viewed under intense magnification, the lesion can be seen to contain small, cumbersomely shaped trabeculae ofbone which form a pseudomosaic structure. A seam of osteoid is also visible. The stroma is loose and has been infiltrated in places by lympho- cytic matter. HE. $500 \mathrm{X}$. 
Fig. 55. Hypertrophie trabeculae of bone charac- terized by the presence of disjointed reversalt ines and deep resorbed lacunae where broad reparative seams of osteoid have been formed. HE. $300 \mathrm{X}$.

The following two chapters contain a more de- tailed consideration of the two groups into which the unclassifiable lesions were divided. Each chapter at- tempts to establish the precise morphological and etio- logical characteristics of the lesions in the particular group it is considering. To this end, the cases pre- sented in the literature which might be of a similar nature were compiled and then compared with the rel- evant case material from the present study. Although it was already clear at this stage that this undertaking might, provided that a sufficiently representative number of cases were available, result in the isolation of possible new entities, there did not at that time seem to be any particular reason to assume that find- ings would be produced which would make it neces-sary to reevaluate all the case material used in the present study in its entirety.

Lesions of Nontumorous Origin: A Consideration

An analysis of those lesions which were poorly defined and which radiological and clinical examinations had found not to be tumoraus sbowed that 'they all had two mor- phological characteristics in common: they all exhibited the radiological symptoms of dysplastic alterations which one would nor- mally associate with fibrous dysplasia, and they were all characterized, histologically, by the presence of reparative bone formation.

The most remarkable histological characteristic of this group is that intense bone remodelling and reparative processes occurred simultaneously in all cases. As a re-sult, large quantities of bone were 
always present (fig. 53), and these were sometimes arranged into mosaic-like structures (fig. 54-

56) similar to those found in cases of Paget's

disease. The trabeculae oflamellar bone have no apparent structural function (fig. 57), and in those cases where the lesion occurred in the jaw, they were always grouped tagether 


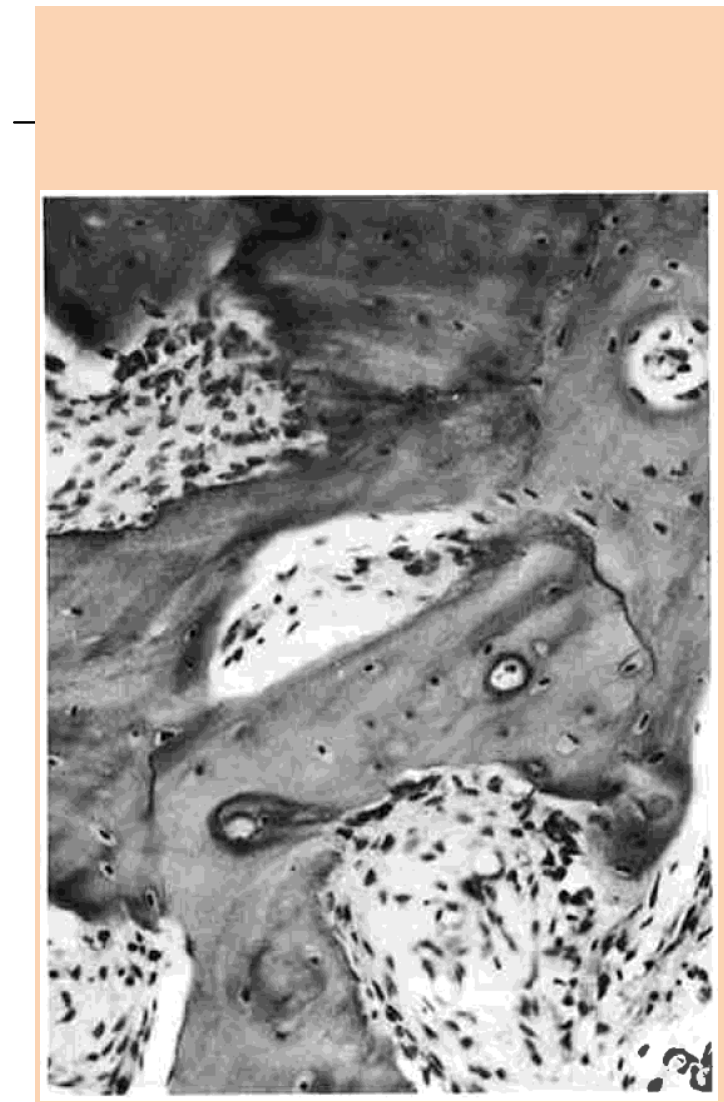

Fig. 56. The stroma is loose and contains lamellae of bone tissue which have been broken and then joined together again by osteoid formations. HE. $160 x$.

into parallel curves (fig. 58,59 ). The cortical bone is leaved and cancellous in appearance (fig. 61). It has been extensively attenuated (fig.60), at the same time, the trabeculae of spongiosa have become abnormally large, so that they are now in fact !arger than the lamellae of cortical bone themselves. Subpe- riosteal formation of new bone tissue was not observed in any of the cases considered and the periosteum always bad a soft texture. The trabeculae of bone present bad a 
markedly lamellar construction (fig. 62). They were subject to intense resorption by large num- bers of osteoclasts. Osteobiasts also occurred, in close proximity to the osteoclasts, and

Fig. 57. Curved broad lamel- lar trabeculae of bone grouped tagether in a sort of mesh. Ra- diologically they are reminiscent of a fingerprint. HE. $63 \mathrm{X}$. 
could be seen to be covering the resorbed tra- beculae with osteoid (fig. 63, 64). The large numbers of osteoclasts which occur and the extent to which they resorb the trabeculae are clear indications of the rapid pace at which these continuous transformations take place. The process is chronic. The stroma is gener- ally loose, though it always contains some areas of increased density where osteogenesis can be seen to be in progress (fig. 65). Even when the lesions have been present for several years, the mesenchyme's osteogenetic potential is in no way diminished.

Fig. 58. The parallel lamellae of bone are gnarled and very thick. The stroma has a high collagenaus fiber content but is present in only very sparse quanti- ties, as can be seen from the fact that the processes used in making the histological slides have caused it to shrink to such an extent that gaps have appeared between the lamellae. HE. 40 X.

Fig. 59. Trabeculae of bone with a markedly la- mellar structure. The lacunae contain osteocytes and the stroma has a high collagenaus fiber content. HE.

$63 X$. 
Fig. 61. Though curved and lamellar, the trabeculae of bone have clearly not been produced randomly. They arealso broader than the surface cortex. The periosteum has remained intact. The Stroma has a high collage- nous fiber content and contains loose lymphocytic infiltrations. Note the broad, thinwalled blood vessels. HE. $63 \mathrm{X}$. 


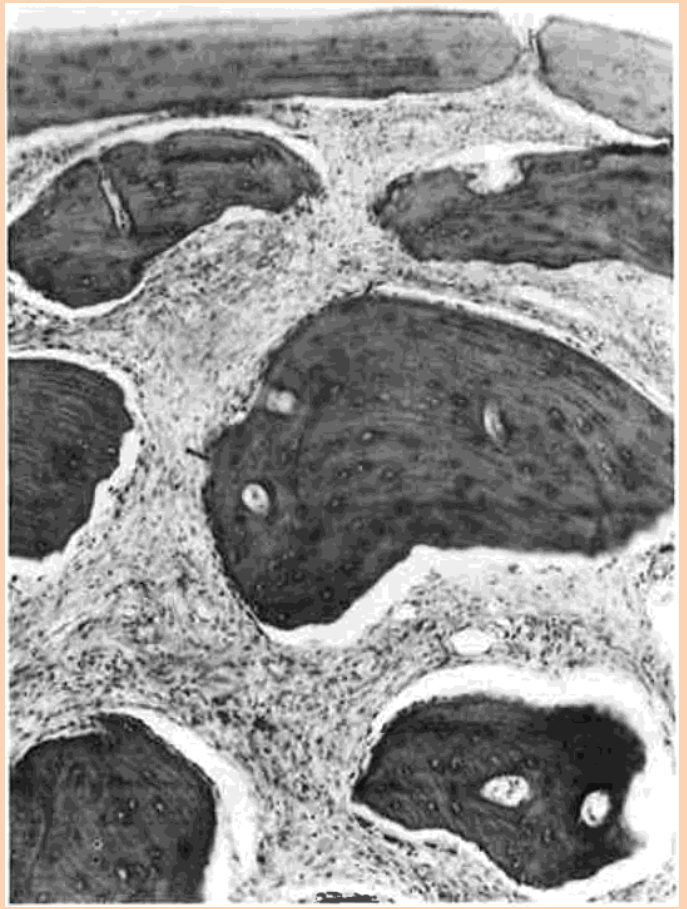

Fig. 60. When the lesion is viewed under greater magnification the characteristically short and very broad shape ofthe trabeculae ofbone is clearly appar- ent. The cortex has been transformed into spongiosa- like tissue. HE. so X. 


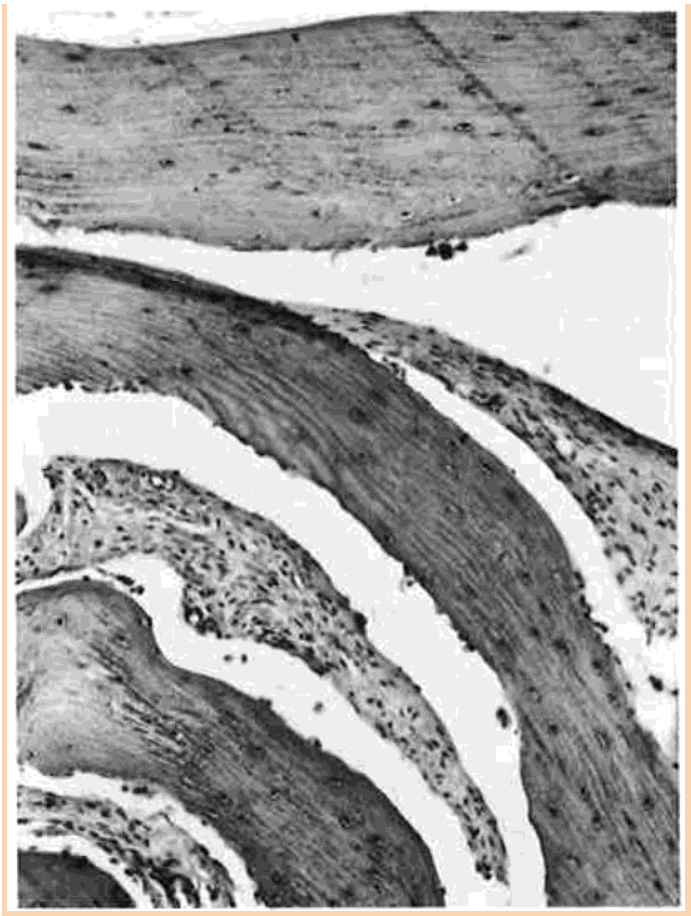

Fig. 62. The stroma is sparse and has a relatively low cell density. It contains curved, very broad lamellar trabeculae of bone, some of which are punctuated by jagged resorption lines. HE. $100 \mathrm{X}$. 
The histological characteristics described above strongly suggest that the principal process at work in such cases is accelerated re- parative bone remodelling. For this reason it seems important that this discussion offibro- osseous lesions should include a close consid- eration of the phenomenon of reactive bone formation.

Bone tissue undergoes continuous renewal throughout life. This transformation is carried out by osteoblasts and osteoclasts. The function of osteoclastic resorption is to liber- ate ionized calcium and that of osteoblastic bone apposition is to retain it. This contin- uaus process of transformation also makes it possible for the bone to adapt to changes in the forces of extension and compression ex-erted on it, the process can also cause the mass of bone in a particular location to be- come too great or too small. Deteriorations in the bone's structural quality may also oc- cur, particularly in cases where there is a net calcium loss. The ratio of bone resorption to bone apposition normally depends on the mechanical strains placed on a particular sec-

Fig. 63. Section of the pe- ripheral area ofa lamella ofbone in which flourishing reparative processes are in progress. The original reversal lines have been interrupted, the surface of the lamella and the resorbed lacunae have been covered by a layer of newly formed osteoid. The os- teoblasts are extremely active. HE. 320 X. 
tion of bone, the amount of calcium which the osteoclasts can liberate, the amount of calcium which the osteoblasts can retain and the age of the person in question. All these factors have an indirect effect on the skele- ton's structure.

The skeleton is affected by every mechan- ical force exerted on it. This is as true of forces whose causes are external to the skele- on such as injuries, as it is of the traction, compression and torsion caused by normal mechanical forces within the bone and, which, to a certain extent, can be regarded as physiological [Uehlinger, pers. commun.,

Fig. 64. Bizarrely shaped trabeculae of bone in which the bone tissue is simultaneously subject to osteoclastic resorption and osteoblastic bone apposi- tion. The osteoblasts are particularly active. The stroma contains loose infiltrations of lymphocytic matter. HE. $150 \mathrm{X}$. 
Fig. 65. Section from the central area of the lesion. The osteogenic mesenchyme is ac- tive and masses of osteoid are being produced and gradually transformed into lamellar bone. HE. $100 \mathrm{X}$.

1979]. When a bone breaks, it is because the strain on it was temporarily too great. Each section of each bone has its own breaking strain, and if this is exceeded even momen- tarily, fracture inevitably occurs. Chronic traumatic damage, on the other band. occurs as a result ofthe cumulative effect ofindivid- ual moments ofsubcritical strain occurring at regular or irregular intervals [Uehlinger, pers. commun., 1979]. The number of these mo- ments of strain, their order of magnitude and the length of the intervals between them will determine the dimensions and the extent of the darnage to the skeleton.

It is a basic tenet of general pathology that there are only three possible consequences of darnage to tissue, and that these apply to every type oftrauma and every type oftissue. The entire organism can die, the traumatized zone can be fully and completely regenerated (restitutio ad integrum) or eise it can undergo 'reparation', a process whereby the original tissue is replaced by connective tissue. Close examination of what happens to a bone after it has been fractured shows that osteogenic mesenchyme has the unique 
quality of being able to effect a complete restoration of the broken bone's functional and morphological properties, and to achieve this without hav- ing recourse to cicatrization. This process would therefore correspond to the second possible consequence of darnage to tissue mentioned above, i.e. restitutio ad integrum. Although there is no lack of cases in which, death, the first possible consequence, oc- curred, the literature does not appear to $d$ - scribe what characteristics one would expect toseein cases ofreparation, the third and last possibility. This is probably due to the partic- ular way in which all bone tissue reacts: when bone tissue is chemically, bacterially or otherwise damaged, it always reacts by mo- 
- bilizing its marrow tissue, thus causing the bone in the affected area to be replaced by newly formed bone tissue. This is generally regarded as a stereotype reaction which auto- matically takes place whenever darnage oc- curs in bone tissue, and it is thought to vary only in its duration, location and intensity. This regenerative process, which not only produces tissue but also determines its shape, is found throughout the animal a!ld plant kingdoms. The normal regenerative process coincides not only with an increase in the number of cells present, but also causes spe- cial cells to be produced, whose structure and dimensions are characteristic and which vary according to the organ or the type of tissue in which they occur. Regeneration is therefore not only a process which replaces damaged tissue, it is also one which restores that tissue's functional properties as quickly as possible. Regenerative processes which are regarded as pathological from a clinical and a morphological point of view occur not be- cause the affected tissue has lost its regenera- tive potential but rather because it undergoes excessive regeneration, becomes tumoraus and therefore causes functional distur- bances.

Hoppe [1964], for exarnple, reported on a condi- tion he terrned 'pseudo-Paget' and described it as 'a tumour-like thickening of the mandibular body'. He regards alterations of this kind as being due to the fact that isolated areathroughout the rnandible have come into contact with and reacted agairrst sorne agent whose precise properlies he was unable to identify, and that they are therefore in a state of constant irrita- tion. This would result in persistent and excessive bone remodeHing causing a turnorlike enlargernent to occur. Increased osteoclastic activity results in resorp- tion of the living lamellar bone occurring in rnany srnall isolated sites. Narrow filarnents of osteoid, to which Osteobiasts are attached, indicate that the bone is not so much being resorbed as transforrned. The 
remodeHing processes which hone undergoes can vary immensely. Dense fibrillar clumps of highly active osteoblasts surrounded by wide ribbons of osteoid cause islands of woven hone to be produced.

Lievre [1947] describes histologicaHy similar alter-

ations which he sees as heing characterized hy 'un remaniement pagetolde post-traumatique'. He states that posttraumatic hone Iransformations of this kind are clinically and radiologically identical to classical osteitis deformans Paget and only differ from Paget's disease in that they remain restricted to the trauma- tized region. The majority of the lesions ohserved hy Lievre [1947] occurred in the tibia, a fact which is hardly surprising when one considers how exposed it is. He did ohserve the condition in other hones, how- ever, and mentions one case where it occurred in the femur and several cases where the pelvis was affected. When the lesion occurred in the pelvis, the patients were aH found to he horseriders who suffered frequent falls. One interesting feature of the lesions Lievre [1947] presents is the fact that they are all initially restricted to the traumatized zone, then gradually ex- tend to include the immediately adjacent area. Only in very rare cases do they encroach upon other neigh- horing hones. Rohner [1956] published a study oflesions ofthis same type. He observed three phenomena which he regarded as characteristic, and supplies detailed histo- logical evidence to support his views. He found that cases ofthistype were all characterized by the fact that bone remodeHing was intense and strategically local- ized, in such a way that the lines of extension and compression were never affected. The middle layer of the compacta was found to be lamellar and leaved, and the spongiosa subject to 'hypertrophic atrophy'. As a result, the newly formed bone is of a biologicaHy inferior quality and its ability to withstand the strains placed upon it consequently diminishes. The remod- elling process shows no signs of ceasing of its own accord, and continues until it becomes chronic. In Rohner's [1956] view, there may be some analogy between this condition and such chronic pathological processes as chronic glomerulonephritis or cirrhosis of the liver, both ofwhich are slowly developing repara- tive processes resulting from an initiallesion. He also assumes that the way in which these lesions develop may in some way be connected with the local hyper-emia which normally accompanies a trauma. As long as the affected area remained hyperemic, hone resorp- tion would be encouraged. Then, when ischemia oc- 
curred, the condition would become hypertrophically atrophied. The hone marrow in the areas where remodelling occurs is extremely highly vascularized, a fact which in Rohner's view shows the immense signif- icance of posttraumatic circulatory disturbances as a characteristic feature of cases of 'remaniement page- tolde'.

In this same study, Rohner [1956] expresses the

view that 'remaniement pagetolde' should be distin- guished from osteitis deformans Paget and classified as a pathological entity in its own right. He states that in hoth processes, the original compacta is trans- formed into hone tissue which appears to be cancel- lous and contains !arge numbers of small trabeculae. While, in cases of Paget's disease, these traheculae appeared to be grouped together into quite arbitrary structures, in the pagetoid lesion their formation ap-pears to have a characteristic, functional structure, most of them being arranged into lines which run along the axis of the affected bone. The fundamental difference between the two conditions lies in the div- erging structures found in the individual trabeculae of hone themselves. In Paget's disease, the traheculae of hone comprise numerous small, irregularly shaped fragments which are joined logether by !arge numbers of jagged reversal lines forming the mosaic structure which characterizes the disease. The trabeculae occur- ring in cases of'remaniement pagetolde', on the other hand, are composed of lamellae which run along the entire length of the lesion, normally along the axis of the affected hone and are only occasionally intersected by soft, curved reversal lines. It would seem fairly evi- dent that these lamellae are in fact remnants of old Haversian osteons which were preserved when the compacta was resorbed. The trabeculae occurring in Paget's disease, on the other hand, are apparently newly formed structures which have replaced the orig- inal compacta. Although X-ray examinations of the trabeculae occurring in these two conditions show both to be lamellarly leaved and although they are radiologically indistinguishable from each other, each is in fact the product of a quite different and distinct process.

\section{Pulschar and Uehlinger [1962] and Villiger and}

Ueh/inger [1978] both describe the pathological char-acteristics of a condition they term 'disseminating giant cell osteodystrophy ofthe tibia'. This syndrome is an insufficiency which occurs in the tibia after it has heen subjected to excessive mechanical strain for a number ofyears. Clinically, the condition is character- 


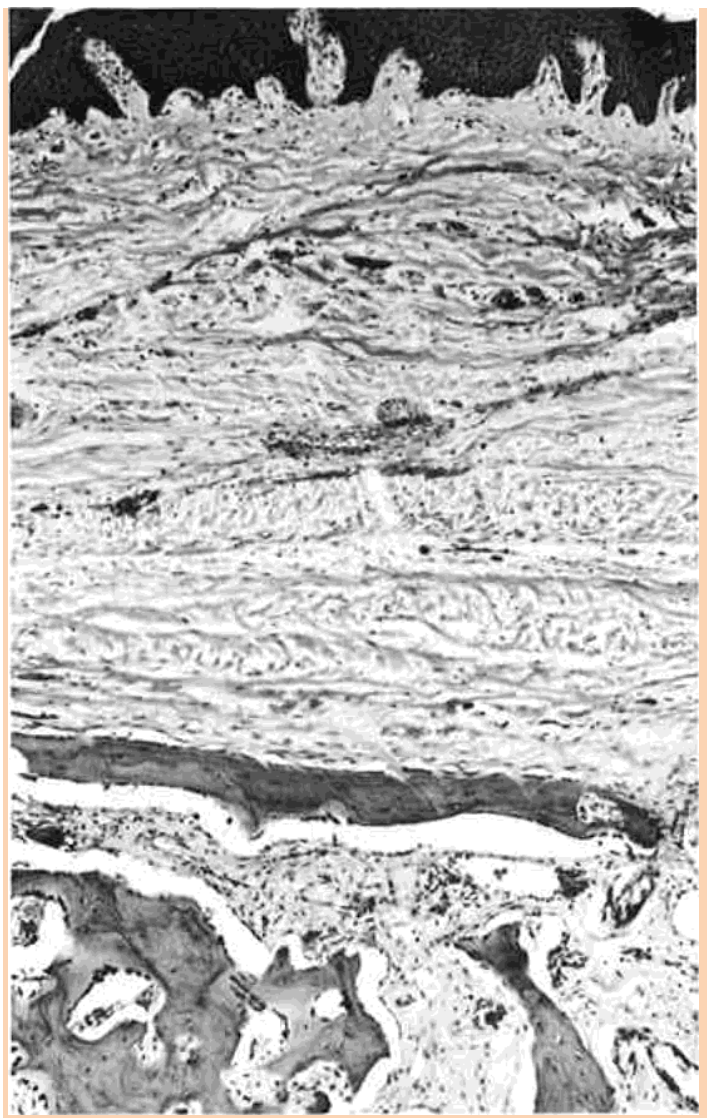

Fig. 66. Material resected from the mandible of a

65-year-old patient with Paget's disease. Mucosa can be seen at the top of the plate and, lower down, the leaved cortex which has now been transformed into a spongiosa-like substance beneath which one can see the lesion itself, with its well-vascularized stroma and hypertrophic trabeculae of bone. HE. $63 \mathrm{X}$.

ized by painful swelling of the soft tissue. This, and the available histological evidence, both support the the- ory that the fundamental cause of the condition is a circulatory disturbance of the diaphyseal region of the tibia. These authors state that this disturbance can be caused either by a single trauma or by excessive strain being placed on the shins for a protracted period of time. The Haversian and Yolkmann's canals in the compacta of the cortical bone were found to be sub- 
Fig. 67. Material resected from the centrat area of the same lesion as the one depicted in figure 66. The process (Paget's disease) is flourishing. The stroma is highly vascularized and the trabeculae ofbone are sub- ject to simultaneaus resorption and apposition, with the result that the lesion inevitably assumes its charac- teristic mosaic structure. HE. 63 X.

stantially expanded, and the compact bone itselfhad a leaved structure. These expanded vascular canals were filled with fibrous bone marrow consisting of spindie cells and having a high blood vessel content. In the areas where the woven bone marrow and the bone itself came into contact, mono- and multinuclear os- teoclasts were found, arranged in chains closely at- tached to the areas of eroded bone.

The case material on which the studies by Pwschar

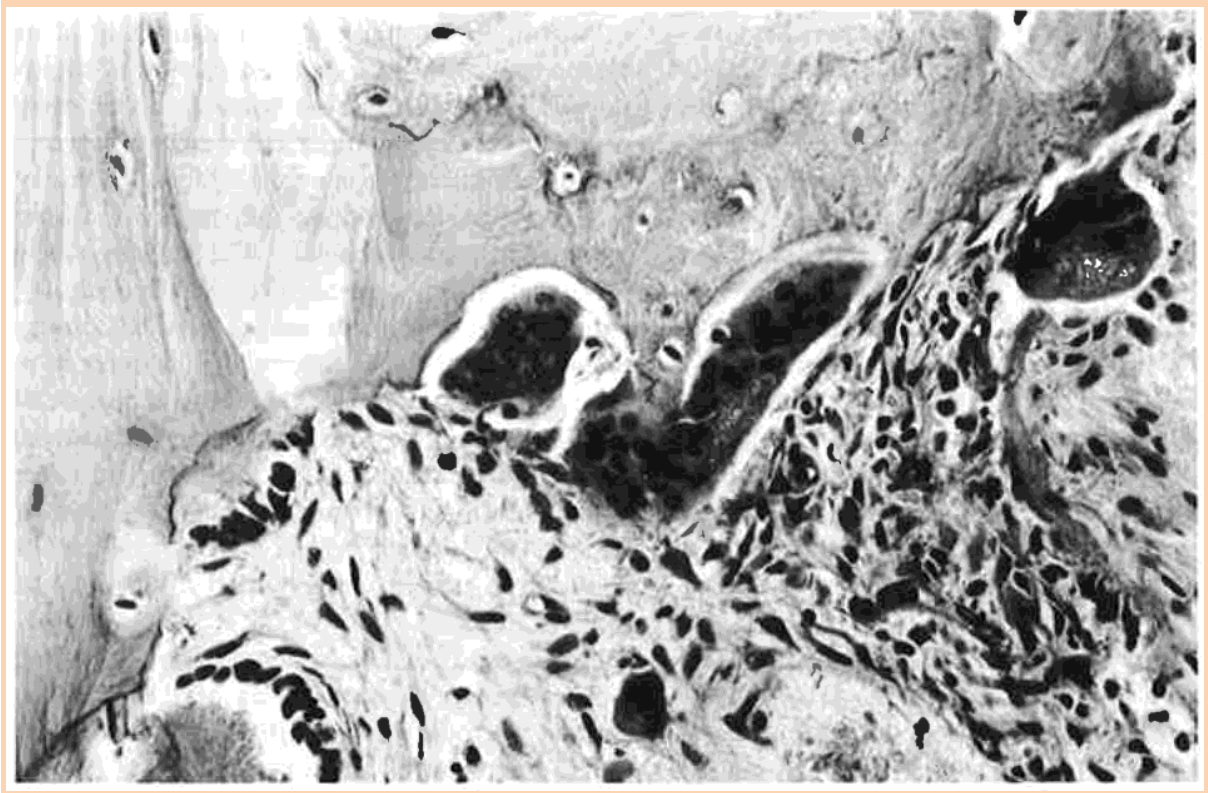

Fig. 68. Typical case of Paget's disease. The bone tissue is being resorbed by !arge osteoclasts and, at the same time, new bone tissue is being apposed by osteoblasts grouped logether into wreath-like formation. HE. 
$250 X$.

and Uehlinger [1962] and Villiger and Uehlinger [1978] are based is in fact drawn from the files ofour clinic, and it was therefore possible to review it in greater detail than would otherwise have been possi- ble. In all the cases, the fact that the cortical bone had a leaved structure, coupled with the appearance of a pagetoid formation, made the conditions very remin- iscent of Paget's disease. Although the precise etiology ofPaget's disease is not yet known, research in recent years has produced some interesting new findings. Rebe/ et al. [1974], for example, state that in four cases of Paget's disease, they observed that viral particles were enclosed in the nuclei of the osteoclasts and that they regarded this as being characteristic. Further studies [Mi//s and Singer, 1976; Mil/s et al., 1979], which were based on ultrastructural findings, corrobo- rate the latter on this point. Mil/s and Singer [1976] and Mil/s et al. [1979] both regard these osteoclastic nuclei's inclusions as providing possible indications that Paget's disease might in fact be of viral origin. They put forward the view that the condition might be a 'slow viral infection ofthe bone' and compare it both with 'subacute sclerotic panencephalitis' (SSPE) and 
- Creutzfeldt-Jakob syndrome. The enclosed particles of viral matter were very similar in appearance to the viral nucleocapsids found in the brain cells of patients suffering from SSPE. Only the osteoclasts occurring in areas affected by Paget's disease were found to contain viral particles of this type. In cases of Paget's disease, these viral particles were found exclusively in the osteoclasts of the affected area. They did not occur in the osteoblasts or osteocytes, nor did they occur in the osteoclasts found in any other pathological bone con- dition or in those of normal healthy bone.

Mi//s et al. [1979] were the first to succeed in pro-

ducing a culture of osteoclastic cells which they man- aged to isolate from bone tissue excised from an area affected by Paget's disease. They found that the nuclei of some of these cultured cells also contained viral particles of the type described above. These findings made the hypothesis that Paget's disease was of viral origin considerably more plausible. In the circum- stances, the view that the condition's characteristic mosaic structures, leaved cortex, hypertrophic atrophy and accelerated bone remodeHing (fig. 66-68) could all be explained by its beingofviral origin seemed tobe a

theory which was at least tenable. This raises the ques- tion of whether fibro-osseous lesions, such as fibrous dysplasia for example, could possibly be of inflamma- tory origin.

As early as 1935, Furedi put forward this view,

after she had examined biopsy specimens of fibrous dysplasia and found morphological evidence of inflammation. Hauston [1965] describes three cases of fibrous dysplasia occurring in conjunction with inflammation, though he regards these inflammations as superinfections of existing fibrous dysplasia and not as a concomitant symptom in the strict sense ofthe term. Filzpatrick [1966] describes an interesting case of 'fi- brous dysplasia' accompanied by inflammation and localized in the mandible. His examinations showed that the inflammatory process had originated in an apical abscess.

Lautenbach and Dockhorn [1968] published a study covering a total of 34 cases of a 'special type of fibrous dysplasia' (this study is described in greater detail in chapter 5). The authors provide a very precise morphological and clinical description of these cases. From the evidence they put forward, it is reasonable to deduce that the conditions were inflammatory pro- cesses. These authors described the condition as iso- lated dystrophy of the jaw. Two studies which are remarkably similar and yet 
mutually Contradietory are those by Jacobsson et al. [1975] and Jacobsson and Heyden [1977]. The first considers 15 patients exhibiting intermittent growth of the affected section of the mandib1e and concomitant pain and swelling. These intermittent bouts bad a duration of 1-2 weeks. As one wou1d expect in a fibro-osseous lesion, only one half ofthe mandible was affected in each case. Radiological examinations re- vealed the presence of osteolytic and sclerotic regions as weil as new bone formation in their periosteal region, this last phenomenon being observed predom- inantly in younger patients. In the later phases of the process's development, the majority of the affected area was covered by sclerotic formations. The authors explicitly state that the condition is very similar in appearance to an osteomyelitic process, and they de- fine it as 'a specialform offibro-osseous lesion'. They describe the results of their histological examinations as follows: 'A constant finding in these cases was poorly oriented trabeculae of various thickness, and these trabeculae were either not calcified or only semicalcified. In two cases, woven bone spiculae were seen, which are characteristic of fibrous dysplasia. 
-Furthermore, bone spiculae with rimming of osteo- blastic cells were seen in three cases, but these also showed trabeculae without osteoblastic rimming. In two ofthese cases, multinucleated giant cells were seen also. Inflammatory cells were also found in one ofthe biopsy specimens, making the diagnosis of chronic Osteomyelitis questionable ...' The authors concluded by saying: 'The present cases differ both clinically and radiographically from the dassie form of fibrous dys- plasia, although the histopathologic features in many cases are in accordance with that type of disease. How- ever, there are some patients in whom the histopatho- logic features are confusing or uncertain. We are aware, therefore, that among these cases there might be concealed other types of fibro-osseous lesion and!or even Osteomyelitis. Further study might reveal their true nature.'

In the study of Jacobsson and Heyden [1977], the authors change their diagnosis of the condition to chronic sclerotic Osteomyelitis. A!ling and Martinez [1975] comment on Jacobsson et al. [1975], stating that examination of their own case material, which they regarded as clinically and histologically identical tothat used by Jacobsson et al. [1975], had prompted them to diagnose 'reactive hyperplasia of the bone'. They went on to suggest that the pathogenesis of lesions of this type lay in intrinsically insignificant traumas, such as might be caused by tooth extraction and similar injuries. They described the process as predominantly proliferative and found that in its var- ious stages of development its appearance was similar tothat of other fibro-osseous lesions. Alling and Martinez [1975] conclude by saying: 'The final expression of the lesion may be designated as eilher a centrat osteoma or sclerotic bone, or a similar phrase may be used.'

That these poorly delineated processes may be confused with fibrous dysplasia when subjected to radiological examination is per- fectly understandable. Histologically speak- ing, however, they are two quite distinct processes. The histological component oftbis reparative process arelamellar bone, pseudo- pagetoid structures, more or less total resorp- tion of the cortex and ubiquitous infiltration of the fibrous marrow by lymphocytes and plasma cells. In other words, the osteoblasts 


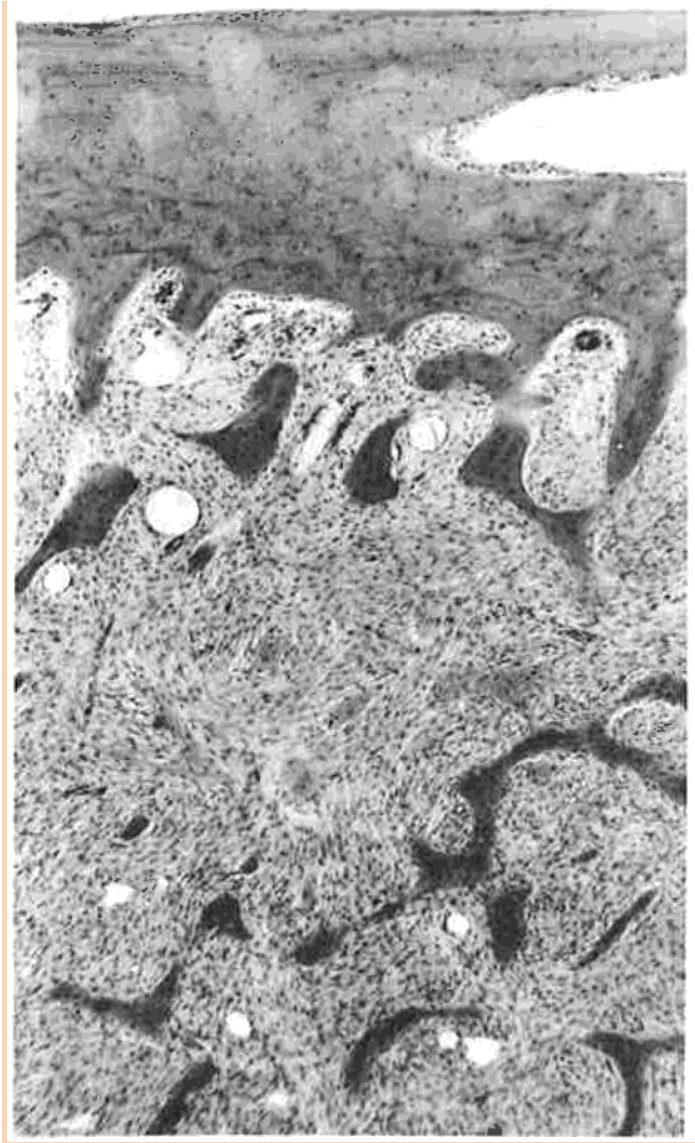

Fig. 69. Typical case of fibrous dysplasia. The or- dinary bone tissue has been replaced by osteogenic mesenchyme composed of spindie cells. Some of the lamellae are delicate and curved. The cortex is attenu- ated and is of lamellar composition. The periosteum has remained intact. HE. $50 \mathrm{X}$.

found in the reparative process referred to above have the ability to produce mature lamellar bone, and it is this feature which distinguishes them from fibrous dysplasia (fig. 69, 70).

Fibrous dysplasia originates in the osteo- blasts, that is to say, the condition is primarily caused by the fact that the osteoblasts 
density. It contains dehcately shaped trabeculae of metaplastic woven bone similar in appearance to Chinese letters. The blood vessels are greatly dilated. HE.

$40 X$

in the affected area are able to produce im- mature woven bone only (fig. 71). The fact that fibrous dysplasia is the only lesion in which the bone tissue produced is exclusively woven is very useful for the purposes of dif- ferential diagnosis, since it makes it possible to distinguish fibrous dysplasia from repara- tive processes, where maturelamellar bone is 


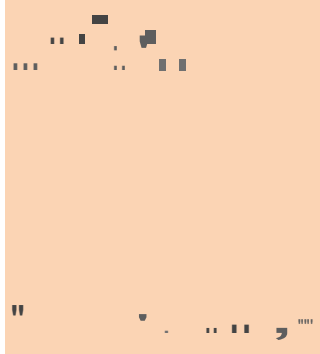

'...' । 
."

- $\quad<\cdot-\quad>1, r^{\prime} \cdot 1$

, 11.

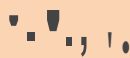


t

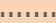

I

.J

(4)

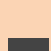


; 
, -71

$\bullet$ 
, 11 I

Fig. 71. Typical case offibrous dysplasia viewed under intense magnification. The osteogenic mesenchyme is dense and delicate trabeculae of woven bone have been formed. HE. $200 \mathrm{X}$.

found. Frost [1966] found that the collage- nous fibers of the osteoid in the woven bone occurring in fibrous dysplasia were arranged in entirely random formations and that the development oflamellar bone tissue was thus entirely precluded. This evidence raises three important questions: whether the cases con- sidered by the present study might not also be of inflammatory origin or initially caused by a disturbed defensive reaction to some exter- nal damage; whether, assuming that tobe the case, the lesion's etiological development might not begin with a trauma, a bacterial infection or possibly even a virus; whether the hyperreactivity in the osteogenetic me- senchyme which disturbs the remodelling process in the first place might not be caused by some form of immunization. The pres- ence of lymphocytes and plasma cells aceur- ring at regular intervals, the continuous re- 
modeHing process being carried out by the active mesenchyme cells and the clinical characteristics of these conditions all suggest that the three questions asked above should in all probability be answered in the affirma- tive. It should be noted that the terms inflam- mation and infection are not synonymous. The former refers to the reaction of the tis- sues to injury, whether chemical, thermal, bacterial or of some other nature, whereas the latter is used to describe invasion ofthe body by living pathogenic microorganisms. Since it arises in the course of interaction with the environment both within the body and out- side it, an inflammatory process remains rel- atively uniform throughout the various stages of its development. It is a biological stereotype with a hast of variations. Inflam- mation is a process which itselfevolves as the organism in which it occurs develops. It is 
Fig. 72. Excess bone tissue formation in a case of chronic sclerosing Osteomyelitis of the tibia (8-yearold male patient). The picture seen is a Chinese ink tracing of an enlargement of the histological slide.

essentially an adaptive reaction, and is therefore biologically expedient.

The features characterizing inflammation described above require it to be described as a special type of activity occurring in injured parts of the body. Such a description would conform to the established principles of counterreaction and self-preservation. This reaction oftissue to inflammation is the basis ofthe phenomenon ofrepair, which includes healing and regeneration. In the repair of tis- sue, the area either becomes replaced with a scar, or the tissue is restored to its original state by the regenerative capacities ofthat tis- sue. An important feature of certain of these forms is an excess of newly formed tissue (fig.

72), which may be temporary, as when a cal- lus forms at the site of a bone fracture. Exces- sive regeneration often proves stable, and has the appearance, for example, of a polypous 
projection or of a tumor-like scar known as a keloid (fig. 73a, b). Hyperproduction oftissue with the development of tumor-like forma- tions can also be seen in the regeneration of peripheral nerves in conditions caused by diastasis and in ulcerative processes in the stomach.

In the light of the evidence presented, it would appear correct to exclude the condi- tion described here from the group of fibro- osteo-cemental lesions. It is of particular importance that a distinction be drawn be- tween this condition and two other entities- fibrous dysplasia and Paget's disease.

Since ra- diological examination shows the lesion tobe poorly defined and since there is no evidence of genuine expansive development, it cannot be regarded as a benign tumor, and it would therefore be inappropriate to classify it as 'osteofibroma' or 'fibro-osteoma' (fig. 74a, b).

Although the condition does have distinct morphological characteristics, its precise etiology remains unknown. In these circum- stances, andin view ofthe similarity between the biological processes at work here and those seen in skin keloid, it is proposed that it be referred to as 'osseous keloid', a term which has the advantage of placing greater emphasis on the lesion's reparative charac- teristics. Examination of the literature and the case material used for the present study suggests that those benign 'fibro-osteo-ce- 
'mental lesions' whose radiological borders are poor, with the obvious exception of Os- teomyelitis in its classical form, should be classified as four distinct entities: (1) fibrous dysplasia; (2) chronic sclerotic osteomyelitis Garn(normally associated with periostitis ossificans); (3) osseous keloid, and (4) Paget's disease.

A substantial number of the cases which the present study defines as osseous keloid were initially diagnosed as fibrous dysplasia. If generally applied, the criteria for the diag- 
Fig. 73. Supposed case of keloid in an apple. The surface has been traumatized (a). The 'tumorous' protrusion can

b clearly be seen (b).

nosis of osseous keloid described here would therefore presumably result in fibrous dys- plasia being diagnosed considerably less fre- quently than it is today. Though in an area in which considerable confusion still reigns as to the terminology to be used to describe lesions and the characteristics to be associ- ated with them, one is naturally loath to abandon any definition of an entity whose existence is generally accepted, it is neverthe- less worth considering that there is one char-acteristic which is intrinsic to dysplastic al- terations in general and fibrous dysplasia in particular, and that isthat they are rare. Fur- thermore, since fibrous dysplasia results in the development of the bone in the affected areas being arrested at the fibrous or 'woven' 
stage, it must obviously be restricted to pa- tients whose skeletal growth and develop- ment is still in progress, i.e. children and ado- lescents.

Fig. 74. a, b. 30-year-old fe-male patient: fibro-osteoma of the maxilla [from Ringertz. 1938]. b 
If fibrous dysplasia has been diagnosed so frequently in the past, and if cases of it have been reported in older patients, then this must inevitably be due to the fact that other characteristics of the condition, which though characteristic are not distinctive, have been regarded as sufficient for a diag-nosis of fibrous dysplasia to be returned. The characteristics which have most fre- quently been used to support what appear to be wrang diagnoses of fibrous dysplasia, and which a number of authors seem to have regarded as entirely adequate for such diagnoses, can be summarized as follows: (I) Radiological characteristics: (a) the fact that all or part of the border surrounding the lesion is poorly defined; (b) the fact that the structural appearance of the lesion is radiologically similar in appearance to ground glass; or (c) to a fingerprint. (2) Clin- ical characteristics: the fact that the bone in the affected area, when cut in the course of surgery, offers a degree of resistance which one would associate with wet sand. This is a well-known intraoperative characteristic of sparsely ossified tissue. (3) Histopatho- logical characteristics: the fact that osteogenic mesenchyme is present and that its principal product is woven bone. In attempting to assess whether any char- acteristic or concatenation of characteristics, be they radiological, clinical or histological, is adequate proofthat one entity only can be diagnosed, it is important to consider what biological processes each of these represents. For example, the fact that the radiological appearance of a particular lesion is similar to that of ground glass merely means that, in the affected portion of bone, the spongiosa one would normally expect to find has been re- placed by osteogenic mesenchyme which is producing regularly distributed trabeculae of 
- newly formed, sparsely calcified bone, and that it has a high collagenaus fiber content. Radiological characteristics of this kind are common in processes of many different types, not all of which are even pathological. The most common examples would be bone healing, reparative processes and inflamma- tion, as weil as certain tumors in which ossi- fication is not particularly intense. An X-ray picture similar in appearance to a fingerprint, on the other band, is caused by the fact that the trabeculae are gnarled, and grouped to-gether into concentric, parallel, elliptical layers. Radiological characteristics of this typearenot usually observed unless a direct contact tooth X-ray was taken and they occur most frequently in cases of the pathological entity which the present study has defined as

'osseous keloid' (p. 105). As to the histo- pathological characteristics, the presence of osteogenic mesenchyme producing bone tis- sue which is not exclusively woven or fibrous cannot be regarded as an indication that the lesion in question is fibrous dysplasia be-cause, since fibrous dysplasia occurs when the affected bone's development is arrested in the fibrous stage, it is not possible for any other type of bone product to be present. Indeed the presence ofany type ofbone prod- uct other than woven bone is in itself a totally adequate reason for stating categorically that the lesion in question is not fibrous dysplasia unless a fracture, be it a large-scale fracture or merely a microfracture, has occurred (in such cases lamellar bone may be present peripher- ally even in cases of fibrous dysplasia). The histological characteristics of fibrous dyspla- sia are described and illustrated in detail else- where (fig. 8-11, 71). It should, however, be stressed that the presence of osteogenic me- senchyme producing bone tissue which is ex- clusively fibrous is not in itself an indication 
that the lesion in question is fibrous dyspla- sia. Identical histological characteristics can be observed in all reparative and inflamma- tory processes.

Pathologists appear to be becoming in- creasingly prone to use the term fibrous dysplasia for an ever !arger group of lesions. Apparently it can now be used even for welldefined lesions which have the ability to re- sorb tooth roots. That at least was the im- pression conveyed by several authorities speaking at a recent meeting of experts on fibro-osseous lesions. The year 1938, when Lichtenstein first isolated the entity, does in- deed seem a long way away.

\section{Lesions of Tumorous Origin: A Consideration}

There is no system in the organism in which a greater variety oftumorous processes can occur than the skeletal system, nor is there a system in which tumors are more dif- ficult to diagnose. The diagnosis of bone tu- mors presents enormaus difficulties, and it is therefore of paramount importance tbat they be approacbed in the right way, with a proper conception of the difficulties involved and a readiness to consider every possibility. The following words of Uehlinger [1959] reflect bis exemplary attitude towards the problems posed by bis work: 'If one conjures up in one's mind the atlas ofbone tumours in all its vastness, and tben compares the histological characteristics of each with the immense va- riety of possible radiological features, one cannot belp but feel bumble. For the surgeon and pathologist alike, the pathology of tu- mours is a very broad field, beset witb diffi- culties. We are but learners in tbis field, and learners we will always remain.' 
Tbe distinction between benign and ma- lignant tumoraus growth alone bas often proved to be bighly problematic. Tbe un-commonly wide range of pathological and anatomical characteristics which bone tu- mors present means that it in no way self-evident how a simple set of adequately descriptive definitions can be evolved wbicb are both generally acceptable and based on common findings. Even today, overlapping and diverging terminology is rife and a number of rival principles of classification are still in use, neitber of whicb factors can be said to facilitate mu- tual understanding in tbis area.

Much work on this suhject was undertaken hy the American College of Surgeons, at a time when, as a then comparatively recently founded hody, its free- dom of action was in no way circumscrihed hy its his- tory. In the 1920s, Codman hegan to collect histologi- cal slides secured from hone tumors and to compile all the clinical and radiological data pertaining to them. The hody of case material he used was relatively !arge and he hoped that hy evaluating it statistically he would gain new insights into the hiology of hone tumors and thus be ahle to estahlish guidelines defin- ing the type of treatment they required. Codman's hasic idea received enthusiastic support from Blood-goodand Ewing, and it was at their instigation that the American College ofSurgeons first set up the 'Registry of Bone Tumors' in 1920, with Codman as its first curator. By 1953, the numher of cases on file had grown to 4,000 and it was decided to transfer the material to the archives ofthe Armed Forces Institute of Pathology (AFIP) in Washington, D.C. Codman puhlished his first results in 1925. His study presents a suhstantially simplified classification, and gives de- tails of the specific locations and age groups in which particular types of tumor occur.

The experience of suhsequent decades showed that, although the majority of hone tumors could he classified according to Codman's parameters, a num- her always remained which were not adequately de- scrihed hy any of the definitions contained in his clas- sifications. The work carried out in this area hy Jaffe and Lichtenstein deserves special mention here. It was 
malignant entities within Codman's giant cell tumor group and defining their characteristic biological be- havior, the localizations in which they occurred and the age groups which they affected. They were also able to show that the entities they had isolated - of which nonossifying fibroma, aneurysmal bone cyst, chondroblastoma and synovitis villonodularis pig-mentosa featuring skeletal involvement are probably the most important - were not genuine giant cell tumors and should therefore not be included in Cod-man's giant cell tumor group. Ackerman and Spjut [1962] drew extensively on the data compiled in the

'Registry of Bane Tumors' and described a total of 25

types of benign and malignant bone tumors. Spjut et al. [1971] published a revised and expanded edition of this Atlas increasing the nurober of tumors described to nearly 50 . This second edition, and a WHO mono- graph by Schajowicz et al. [1972], can be said to mark the close of an era of research work which began with the foundation of the 'Registry of Bone Tumors' in 1920.

In any form ofscientific or practical study, the value of classification and nomenclature is necessarily ambivalent, since both are in- dispensable and fallible at the same time. When a field of study is first explored, the scheme according to which it is initially clas- sified will, of necessity, be based on con- jecture. Once a scheme of classification has become weil established in a field where re- search is still being carried out, it will inevi- tably become increasingly incomplete and inadequate as new discoveries are made. De-spite these inherent weaknesses, some form of generally known terminology is vital in any field of scientific endeavor so that those working in it can communicate with each other in mutually understandable terms.

The experience being gained in this field every day makes it increasingly apparent that a division ofbone tumorsintosuch diametri- cally opposed categories as 'benign', 'malig- nant' and 'tumor-like processes' does not ad- equately reflect the immense variety of the 
clinical characteristics which have been ob- served. In the American classification, these intermediate forms, which present both ma- lignant and benign characteristics, are de-

fined as being of a 'low grade of malignancy'.

The tumors covered by this definition are all slow growing and have the ability to produce remote metastases years, or even decades, later.

Uehlinger discussed the subject of semimalignant tumors with this author on a nurober of occasions. His views on the subject, which he explained and illus- trated somewhat allegorically in a study [Uehlinger.

1976], can be summarized as follows: At the Last Judgment, human beings were divided into benign and malignant Christians. However, it soon became evident that the two-class system was insufficient and it was necessary to introduce a third category. This third group was reserved for Christians who would have a chance of becoming clean in purgatory and entering paradise later. Experience with the biological classifications of tumors was similar: between the be- nign and malignant types there is an intermediate group. In the literature published in English these intermediate bone tumors are called sarcomas of Jow grade malignancy. The German language prefers the term semimalignancy. The two terms do not have quite the same meaning, but are overlapping. Semi- malignancy, a term first introduced by Zollinger [1946], is perhaps best explained as follows: semima- lignant tumors are characterized by local invasive and destructive growth; they have a tendency to recur, but do not metastasize. The intervals between recurrences vary from case to case, lasting weeks, months or years. When semimalignant tumors do recur their histologi- cal characteristics are always identical to those observed when the initial biopsies were taken. The histo- logical characteristics of the first biopsy slides give the pathologist no apparent reason to assume that the Jesion will recur, nor do the biopsiestaken from recur- ring lesions provide any clue as to why recurrence took place. In Uehlinger's view the following bone tumors are classifiable as semimalignant: giant cell tumors, chondromyxoid fibroma, !arge central and epiexostot- ic chondromas ofthe pelvis and villonodular synovitis. He regarded the term Jow grade malignancy as more appropriate for cases of paraosteal osteosarcoma. 
Over the years, the various definitions and clas- sifications which have been applied to odontogenic tumors have evolved in much the same way as those pertaining to bone tumors. The work done by Broca in this field can be seen as the equivalent of that done by Codman in the field of bone tumors and, as was the case with Codman, numerous alterations and additions to the initial classifications, which Broca published in 1866, have since been put for-ward. Gabel/ et al. [I 914] proposed a classification based on histogenetic principles in which they differ- entiated between epithelial, fibrous tissue and com- pound odontoma. Thoma and Goldman [1946] dis- tinguished between odontogenic cysts and genuine odontogenic tumors. They also divided the fibrous tissue odontoma described by Gabel/ et al. [1914] into two entities, fibroma and cementoma. In 1952, the American Academy of Oral Pathology published a revised [Robinson, 1952] classification of odonto- genic tumors. This classification provided an exce1-lent basis from which all those concerned in the therapy of lesions of this type could work. Its only failing was that it overlooked the inductive effect of odontogenic epithelium on fibrous tissue. Findborg and Clausen [1958] were the first to publish a clas- sification of odontogenic tumors which took account of the mutually inductive effect of ectoderm and mesoderm during tooth formation. They differen- tiated between two main types of odontogenic tu- mors, epithelial and mesodermal. The first type, covering epithelial odontogenic tumors, was further divided to form two subcategories, exclusive1y epi- thelial tumors and epithelial tumors featuring induc- tive change in the connective tissue. It was Findborg and C/ausen's [1958] classification which formed the basis for the recommended histological classification of odontogenic tumors contained in the WHO publi- cation of Findborg and Kramer [1971].

Donath [1977] proposed that odontogenic tumors be classified according to five stages of tooth development. Ries and Reichart [1980] evolved a classifica- tion technique which defines the various types of odontogenic tumors in terms of the cell groups they contain. These authors cantend that the histogenetic origin of odontogenic tumors can be determined by the presence or absence of four cell groups (epithelial, ectomesenchymal, neuroectodermal and mesenchy- mal). They state that every odontogenic tumor will contain two of these cell groups, that all six binary permutations are possible, and that each ofthese com- 
- binations characterizes one or several types of odon- togenic tumor. Ultrastructural research and experi- ments can be expected to produce new findings which should provide further information about the biologi- cal behavior of odontogenic tumors and thus facilitate their morphological diagnosis. A consideration of the way in which bone is formed facilitates an understand- ing of the histogenesis of the various types of bone tumor and the locations in which they occur. It is pre-cisely because the way in which the skeletal system develops and renews itself is so complex, that the tumors which occur in it are so immensely varied. As von Albertini [1974] states, every neoplastically prolif- erating cell originales from a specific mether cell. It therefore follows that every neoplastic cell will have the same capacity to produce tissue as the cell in the tissue from which it originales.

Schutz [1980] gives details ofthe highly interesting results the author obtained from an ultrastructural examination of bone tumors. His investigations were extremely detailed and fulljustice can be done to them only ifthey are summarized at some length. The next few pages have been devoted to this task. Schulz's [1980] ultrastructural examinations allowed him to divide the tumor cells present in these lesions into four distinct cytogenetic categories, each of which was characterized by five different phases of development. On the basis of the cytogenetic differences he bad observed, he distinguished between 'chondrogenic',

'osteogenic', 'reticulocytic' and 'monocytic-osteoclas- tic' tumors. He theorized that all four cytogenetic types originated from mesenchymal cells ofa common indeterminate type. His assumption that such a cell form might exist is based on a theory of general embryogenelies which holds that the various cells pro- ducing nonepithelial tissue are all derived from a sin- gle primitive form of 'stem cell'. The present state of knowledge has not yet determined the genetic charac- teristics of these hypothetical 'stem cells', but the assumption is that they will not have reached the stage where they will have to 'choose' one course of cytogen- etic development or another, that the entire spectrum of possible tissue producing 'identities' is still open to them and that they are therefore free to assume any one of them. 1t should, however, be emphasized that these 'stem cells' are purely hypothetical, and that it has not been possible to determine their functional, morphological or cytogenetic characteristics. This hy- pothetical primitive form would therefore be common to all cytogenetic types. For the purposes of this expo- 

sition it can be referred to as stage 0 , and will therefore be followed by stage $\mathrm{I}$, in which the genetically defined parent cells are formed. It is these parent cells which mark the first phase of the various specific forms of cytogenetic development. Although no morphological differences between the different cytogenetic forms can be seen at this stage, each form is clearly defined by the fact that it now has the ability to produce one specific form of tissue and one form only, whereas in stage 0 all the mesenchymal cells theoretically had full genetic potential.

Although these parent cells do not have any spe-

cialized function at this stage, a number of researchers [Young, 1962; Fitton-Jackson, 1965; Vaughan, 1975] have been able to determine the genetic identity of chandrogenie and osteogenic cells in stage I of their cytogenetic development. This was made possible by the use of in vitro and autoradiographic techniques. Ultrastructural examination makes it possible to dis- tinguish between stages I, II, III, IV and V of the cyto- genetic development of all four types of bone tissue producing cells, and from stage II onwards each type is sufficiently functionally specialized for its genetic identity to be apparent under the electron microscope. This cytogenetic model is particularly useful since it shows how neoplastic tumor cell forms and reactive cell forms combine to form the fundamental nutritive tissue or 'stroma' ofthe various types ofbone tumors. In stage I the various types of parent cells differ only in their genetic characteristics, though these, as was noted above, can be determined only in the case of chandrogenie and osteogenic cells at this stage. Mor- phologically speaking, they cannot be distinguished from each other, since ultrastructural examination does not reveal any noticeable variations in the forms of the various nuclei or cytoplasms. In stage II, func- tional specialization begins, and the composition of the organelies in the various cell forms becomes no- ticeably characteristic. Functional activity is either -absent in stage II or has barely begun.

The way in which these immature chandrogenie and osteogenic cells proliferate has induced some authors to define them as 'prechondroblasts' and 'preos- teoblasts' [Owen, 1963; Pritchard, 1972]. It is in stage III that the specialized functional activity of the various cell forms begins. The behavior of osteoblasts when they reach stage IV of their development is par- ticularly interesting. Their morphology undergoes a marked transformation. They become apolar and be- gin to produce fibrous osteoid which has the ability to 
- become mineralized. With the exception of osteoma, all osteogenic tumors have a stroma offihraus osteoid which differs from that found in normal bone tissue. Provided their periodicity is normal, the mineralized and nonmineralized collagenaus fibrillae contained in the stroma ofbone tumors can clearly be seen to have a substantially smaller diameter than those found in the stroma of normal bone tissue. It is characteristic of all osteogenic tumors, again with the exception of osteoma, that the processes whereby they aggregate tropocollagenous filaments are disturbed. In all prob- ability this disturbance is caused by the fact that tumor cells synthesize insufficient quantities of glyco- protein. When they reach stage $\mathrm{V}$ of their develop- ment, osteoblasts become polarized and begin to pro- duce lamellar bone. Eventually, both apolar osteo- blasts producing fibrous osteoid and polar Osteobiasts producing lamellar bone become immured in a mass of bone tissue. When this happens, they normally develop into osteocytes. The cytogenetic development process described above is a model based on the func- tional and morphological characteristics of the var- ious cell types which can be observed under the elec- tron microscope. Since it has proved a useful tool for the examination of the pathogenesis of the bone tu- mors considered in the present study, it seemed ap- propriate that it should be exposed in some detail. One of the aims of Schutz's [1980] study is to provide a clear picture of how the various types of osteogen- etic tumor he considered are formed. It was with a view to achieving this that he evolved this cytogenetic model as a means of examining his case material. The main finding that his examinations produced was that the cellular components of all osteogenic bone tu- mors, except those of osteoma, consisted exclusively of tumoraus and reactive cells. There can, however, be morphological differences between cases in which the same osteogenic tumoraus entity has been diagnosed. These differences are caused by the fact that the tumor tissue in one case may be dominated by tumor cells which have reached one particular stage of cytogenetic development, whereas in another case of the same entity tumoraus cells in a different stage of cytogenetic development may predominate. Osteo- genic tumor tissue consists of two distinct tumoraus cellular types, neoplastic cells and reactive cells, and, as Schutz [1980] points out, it is important to distinguish between the two of them. It is reactive cells which produce most of the giant cells found in osteo- genic tumors.

Johnson [1953] states that the precise nature of a tumor occurring either in growing or mature bone will depend on which form of transformation process predominates at the site of its orthogenesis. He 
goes on to point out that individual types of tumorous process are specific to individual types of tissue and that it therefore follows that they can occur only in locations where those individual types of tissue are present.

During the first two decades oflife, tooth development and pneumatization of the facial cavities both cause extensive remodelling in the maxillofacial bones, and it is therefore hardly surprising that neo- plasia and disturbed bone development are common in this region of the skeleton. As was stated in chap- ter 3 , the mesenchyme found in the dental papilla originales embryologically in the neural crest. It was also shown that, in the region of the tooth roots, the mesenchyme of the tooth-supporting tissue (which is composed of fibroblasts, fibrocytes, osteoblasts and osteocytes) also contained dentinoblasts and cemento- blasts originating in the neural crest. Both Johnson [1953] and Basset [1962] take the view that the factors which determine whether a tumor will be osteogenic or chandrogenie are mainly external to the cells con- cerned, and that the special metabolic conditions pre- vailing in a tumorous cell's extracellular environment have a dominant determining effect on the tumorous

'identity' it will eventually assume. This would there-

fore suggest that the way in which tumorous bone cells develop is analogous to the growth processes of the normal bone and cartilage-producing cells which sur- round them.

Theoretically speaking, the number of different cytogenetic types of fibro-osteocementallesion which can occur in the max- illo-facial bones is relatively limited. In fact, the only cells with the potential to form tumors are osteoblasts, cementoblasts and fibroblasts, though a combination of these could also be regarded as a fourth possi- bility. It would therefore seem appropriate at this stage to describe in greater detail the tumors which each of these cell types can produce. 
Tumors of Osteoblastic Origin

There are only three benign tumors of osteoblastic origin, namely: osteoma, osteoid osteoma and osteoblastoma.

\section{Osteoma}

Osteoma is a benign bone tumor charac- terized by proliferation of either compact or cancellous bone in an endosteal or periosteal location. The tumor grows s1owly and causes

1itt1e or no trouble to the patient. The perios- teal lesions manifest themselves as circum-scribed swellings of the jaws that result in obvious, clinically observable asymmetry. In the case of endosteal lesions, considerable lesional growth must take place before ex- pansion ofthe cortical plates is observed clin- ically [Shaferet al., 1974] (fig. 75).

The most common location of osteomas is the skull (fig. 75), though the lesions do occur in the jaws. When the jawbones are affected, the mandible is more frequently involved, and the most common mandibular sites are the lingual aspect ofthe body, the angle, and the inferior border [Noren and Rache, 1978]. Of the two types of osteomas recognized, the cancellous form occurs more frequently in women (fig. 76), whereas compact or cortica1 osteomas are found most1y in men [Pindborg, 1965]. The patients are usually aged between 15 and 30 years. Lichtenstein (1972] regards osteomas, like osteoid osteomas, as a special type of benign osteob1astoma, that is to say that he sees them both as re1ated benign tumor entities of osteob1astic derivation. Aegerter and Kirkpatrick [1975] describe these 1esions as hamartomas of the perios- teum. They be1ieve 
that these lesions are always caused by intramembranaus ossifica- tion and that they are in fact nothing more than exaggerations of a normal physiologica1

process. According to laffe [1958], this lesion may be the terminal ossified stage of fibrous dysplasia. Smith and Zavaleta [1952] and Reed and Hagy [1965] believe that ossifying fibromas may differentiate into more mature osteomas. Halse et al. [1975] point out that osteomas, in whatever part of the skeleton they occur, can be the first clinical symptoms of Gardner's syndrome. They therefore rec- ommend that it should always be borne in mind as a possibility when osteomas are sub- jected to differential diagnosis. 
Osteoid Osteoma

Osteoid osteoma is a distinct benign enti- ty. It has a nidus less than $2 \mathrm{~cm}$ in diameter (fig. 77) composed either of immature os- teoid, woven bone or a mixture of both. The nidus causes considerable pain and can often provoke reactive sclerosis in the contiguous tissue of the host bone (fig. 78). Pain is very characteristic of this lesion and is accompa- nied by vasomotory disturbances, such as increased skin temperatures in the affected region and profuse perspiration. Sherman

Fig. 75. Cross-section of the roofofthe skull ofa 65 -year-old female patient. Note the com-pact osteoma or 'exostosis' (courtesy of Prof. E. Ueh/inger. Zürich). 
Fig. 76. Osteoma spongio- sum ofthe mandible. The tumor is weil defined and has the same structural characteristics as the adjacent spongiosa (51-year-old male patient).

and McFarland [1965] found that the blood vessels in the reactive fibrous zone surround- ing the nidus were accompanied by nonmye- linated nerve fibers and postulated that these might be the cause of the pathognomonic pain occurring in cases oflesions ofthis type. Byers [1968] described several such lesions where axonal fibers occurred singly or in pairs and coursed irregularly through the stroma.

Schulman and Dorfman [1970] pos- tulated further that the pain was generated and transmitted by autonomic nerves sensi- tive to vascular pressure. This lesion occurs predominantly in children, adolescents and young adults between the ages of 10 and 25 years. It is distinctly rare in patients aged more than 30 .

Overall, the lesion occurred twice as often in males as in females. Lesions of this type are rare, especially in the ribs. 
-Table XIV provides details of 8 published cases of osteoid osteoma occurring in the mandible, while table XV lists 6 cases where the lesion was reported in the skull.

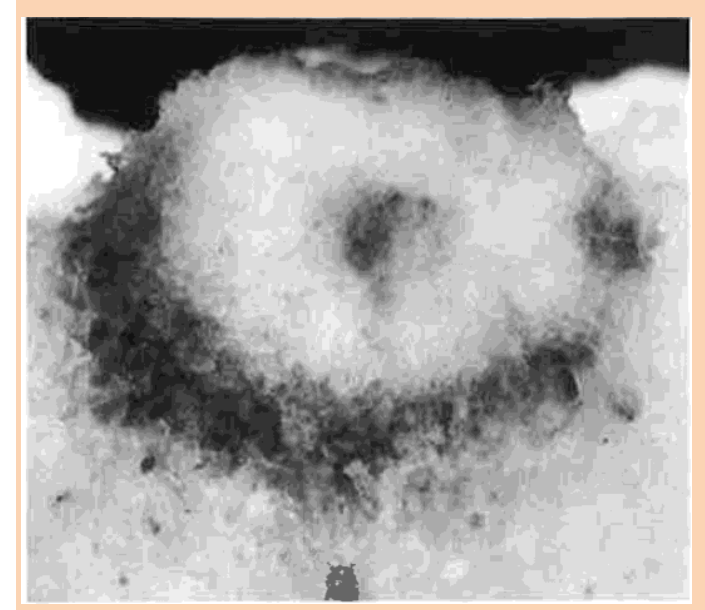

Fig. 77. Macroscopic view of material resected from a typical case of osteoid osteoma. The nidus is centrally located, there is a seam of sclerotic matter and the Jesion is well defined. 
Fig. 78. Overall view of a typical case of cortical osteoid osteoma. The nidus is small and there are unmistakable signs of reactive sclerosis. The original borders of the cortical bone can clearly be seen. The medulla is practically unimpaired. HE. Ac- tual size.

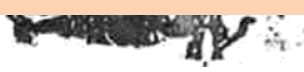



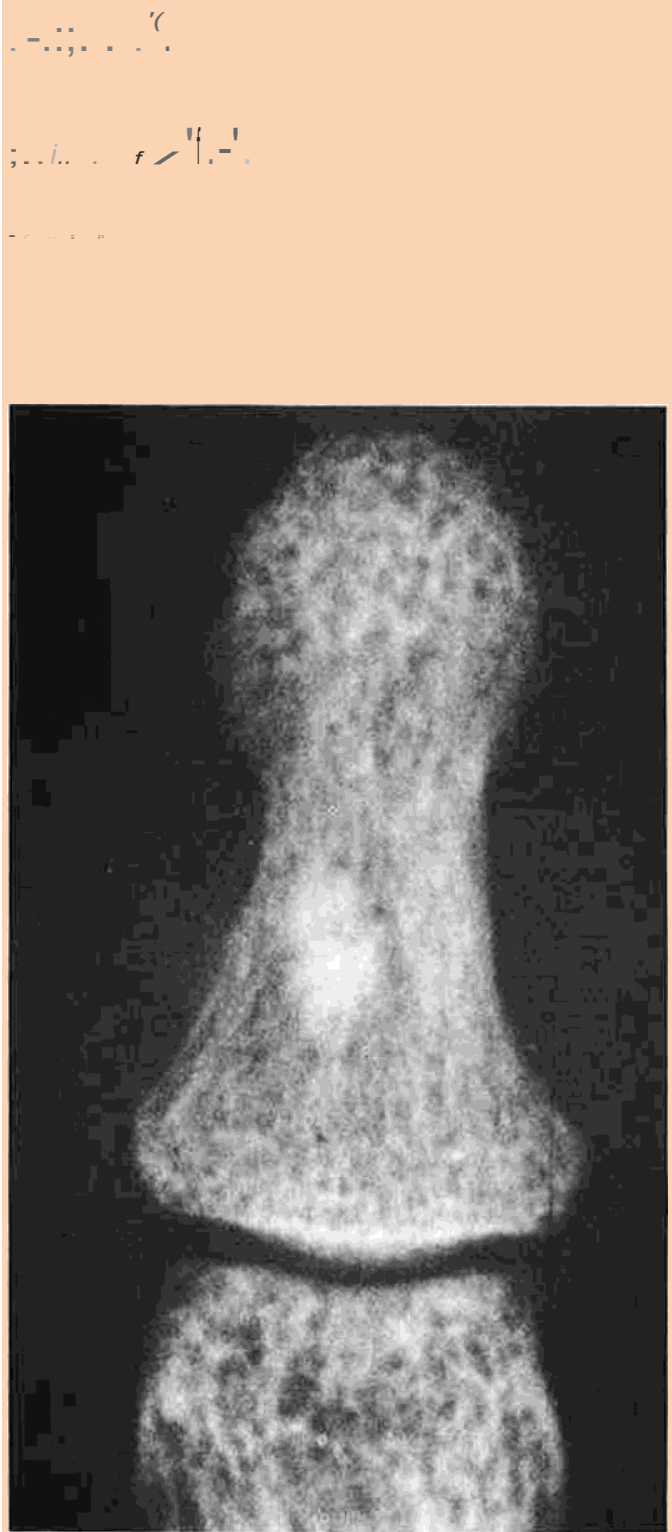
Fig. 79. Radiological view of an osteoid osteoma of the index finger. The area in which hone sclerosis is in progress is well defined and has a small nidus at its center (courtesy of Prof. E. Uehlinger, Zürich). 
Fig. 80. Histological view of a case of active os- teoid osteoma. The stroma is loose and weil vascularized and contains !arge quantities of osteohlasts. The hone tissue produced has a low cell density. HE. $280 X$

Table XIV. Puhlished cases of osteoid osteoma of the jaws

Case

Author(s)

Year

Age

Sex

Site

Pain

Rushton

1951

27

M

mandible

yes

2

Foss et al.

1955

26

F

mandihle

yes

3

Nelson 
M

maxilla

yes

4

Stoapack

1958

25

M

mandihle

no

5

Lind and Hilierstrom

1964

48

M

mandihle

yes

6

Hilimann and Birck

1965

4

F

maxilla

?

7

Greene et al.

1968

45

F

maxilla 
8

Jurgens

1968

16

M

mandihle

yes

Radiological examination is the single most reliable aid to diagnosis (fig. 79). The lesion's characteristic radiological features are: (1)A central spherical or oval area of high bone density usually less than $1 \mathrm{~cm}$ in 
diameter (the 'nidus'). (2) A thin (1-3 mm) collar of lucency surrounding the nidus. (3) The periosteum and the contiguous host bone may acquire a density similar tothat of the tumor itself. How far this extends will

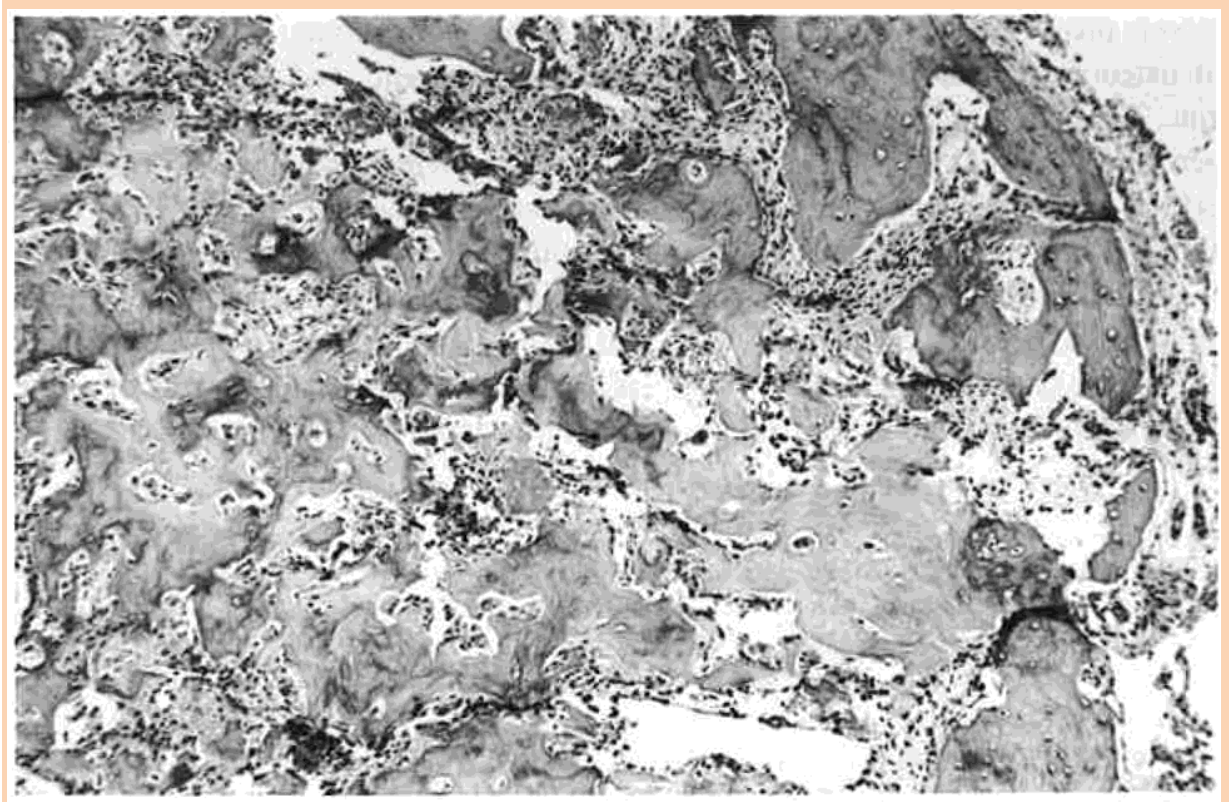

Fig. 81. Case ofmature osteoid osteoma. The trabeculae ofbone are broad and characteristically shaped.

The stroma is weil vascularized and there are osteoblasts between the trabeculae. HE. $65 \mathrm{X}$.

Table XV. Published cases of osteoid osteoma and Osteoblastoma of the skull

\begin{tabular}{|c|c|c|c|c|c|c|c|}
\hline Case & Author(s) & Year & Age & Sex & Site & Pain & Diagnosis \\
\hline I & Payrau and Perdrie/ & 1956 & 21 & & orbit & yes & osteoid osteoma \\
\hline
\end{tabular}


Examination of the Case Material and Conclusions

$\begin{array}{llllllll}2 & \text { Tänzer } & 1959 & 50 & \text { F } & \text { ethmoid } & \text { yes } & \text { osteoid osteoma } \\ 3 & \text { Munk et al. } & 1960 & 48 & \text { M } & \text { frontal bone } & \text { no } & \text { osteoid osteoma } \\ 4 & \text { Via/let et al. } & 1967 & 4 & \text { M } & \text { occipital hone } & \text { yes } & \text { Osteoblastoma } \\ 5 & \text { Reinhardt } & 1972 & 44 & \text { M } & \text { parietal bone } & ? & \text { osteoid osteoma } \\ 6 & \text { Prabhakar et al. } & 1972 & 21 & \text { M } & \text { frontal hone } & \text { yes } & \text { osteoid osteoma } \\ 7 & \text { Da/y } & 1973 & 24 & \text { F } & \text { temporal hone } & \text { yes } & \text { osteoid osteoma } \\ 8 & \text { Ronis et al. } & 1974 & 13 & \text { M } & \text { temporal hone } & \text { no } & \text { osteoblastoma }\end{array}$

vary from case to case. The main difficulty in radiological diagnosis is that osteoid osteoma often causes such dense sclerosis in the sur- rounding host bone that the nidus is totally obscured on routine X-rays.

Huvos [1979] distinguishes between three

distinct evolutionary stages of nidification. The initia1 stage is characterized by the pres- ence ofactively proliferating, densely packed, prominent osteoblasts in a high1y vascular- ized stroma. This picture changes gradually and imperceptibly into an intermediate phase in which osteoid is deposited between the osteoblasts. The extent to which these patches of osteoid are mineralized is subject to topographic variation (fig. 80). This is the most characteristic phase ofthe lesion's evo- lution. In the lesion's mature stage, the os- 
teoid is transformed into well-calcified, com- pact trabeculae of atypical bone, which are histologically peculiar since they are neither typically woven nor typically lamellar (fig. 81 ).

Osteoid osteoma may present a baffling diagnostic problern because the clinical symptoms, especially pain, may occur long before the characteristic radiological findings become apparent, and many mo ths may pass before a definite diagnosis can be made. It is highly regrettable that several patients have been regarded as malingerers or psycho- neurotics and unnecessarily referred for psy- chiatric consultation in search ofthe etiologi- cal agents of their pain [Silberman, 1962]. It is obvious that the small number of reported cases of osteoid osteoma in the mandible and

Table XVI. Published cases of osteoblastoma of the jaws

Case

Author(s)

Year

Age

Sex

Site

Pain

I

Bore/la and Sedano

1967

21 


\section{Kramer}

1967

6

$\mathrm{F}$

mandible

yes

3

Byers

1968

\section{mandible}

yes

4

Kent et al.

1969

13

F

maxilla

yes

5

Kopp

1969

19

M

coronoid proc. of mandible

no

6 
1970

maxilla

yes

7

Brady and Browne

1972

19

M

mandible

yes

8

Brady and Browne

1972

14

M

mandible

yes

9

Smith

1972

7

M

mandible

yes

10

Wickenhauser et al.

1973

5 
maxilla

no

| |

Yip and Lee

1974

22

F

maxilla

yes

12

Remagen and Prein

1975

15

M

mandible

no

13

Labayle et al.

1976

15

M

maxilla

no

14

Greer and Berman

1978

30

M

mandible

no 
15

Chatterji et al.

1978

30

$\mathrm{F}$

maxilla

yes

16

Nowparast et al.

1979

14

$\mathrm{F}$

mandible

yes

17

Mil/er et al.

1980

37

F

mandible

yes

18

Miller et al.

1980

6

M

mandible

yes

19

Mil/er et al. 
maxilla

yes

20

\section{Danielidis et al.}

\section{0}

15

$\mathrm{F}$

mandible

no
Monks et al.
1981
19
F
mandible yes

maxilla precludes any definitive deductions with regard to this lesion's behavior in the jaws. It is not unreasonable to assume that its occurrence in this region is more common than the literature would indicate [Greene et al., 1968].

\section{Benign Osteoblastoma}

Benign Osteoblastoma is a very uncom- mon lesion (table $\mathrm{XV}, \mathrm{XVI}$ ) accounting for about $1 \%$ of all primary bone tumors, with approximately 360 cases reported in world literature. Examination of the reported cases showed that the male:female ratio was 2:1. The average age of the patients concerned was 17 years. Osteoblastoma, although histo- logically related to osteoid osteoma, is a pro- gressively growing lesion of !arger dimen- sio -; is sometimes painful, and is character- ized by the absence of any reactive perifocal bone formation. The pain pattern is not the same as that commonly seen in cases of osteoid osteoma, i.e. it is not nocturnal and is not particularly relieved by salicylates. In general, the lesions, irrespective of their site or 
size, are weil circumscribed, radiolucent, and usually quite expansile (fig. 82). Diasand Frost [1974] proposed a new classification for lesions of this type. Their proposa1s, which are somewhat complex and controversial, have however met with less than universal acceptance.

Although some clinical and radiological differences exist between the smaller osteoid osteoma and the !arger osteoblastoma, these differences are, according to Schajowicz and Lemos [1970], probably due to the fact that the former is located in the cortex while the latter occurs in spongiosa (fig. 83). This would explain the limited growth potential of osteoid osteoma, for which they proposed the designation 'circumscribed osteoblastoma'. 


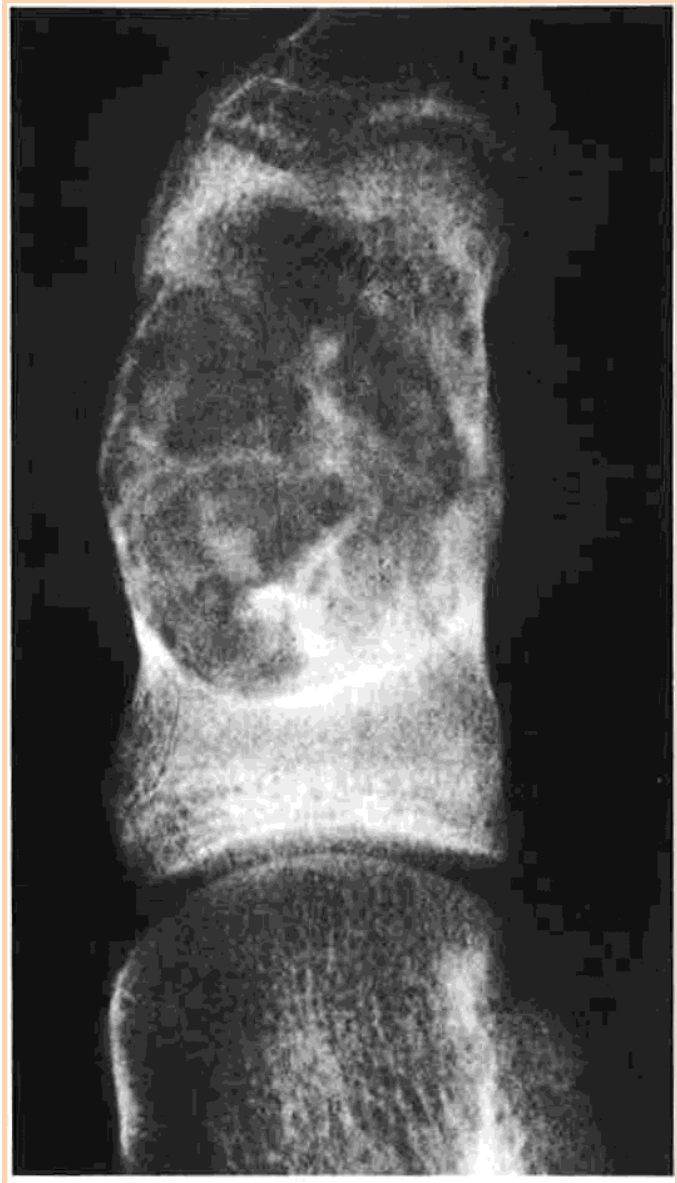

Fig. 82. X-ray of a typical case of osteoblastoma of the big toe. The patient is male and 18 years of age. The lesion appears as an almost polycyclic area of radiolucency and contains randomly distributed foci ofmineralization. The cortex has been severely atten- uated. The nidus is practically indiscernible (courtesy of Prof. E. Vehlinger, Zürich). 
Dias and Frost [1974] introduced the terms

'cortical osteoblastoma' for osteoid osteoma and 'spongious osteoblastoma' for genuine osteoblastoma.

The histological hallmark of an osteoblas-

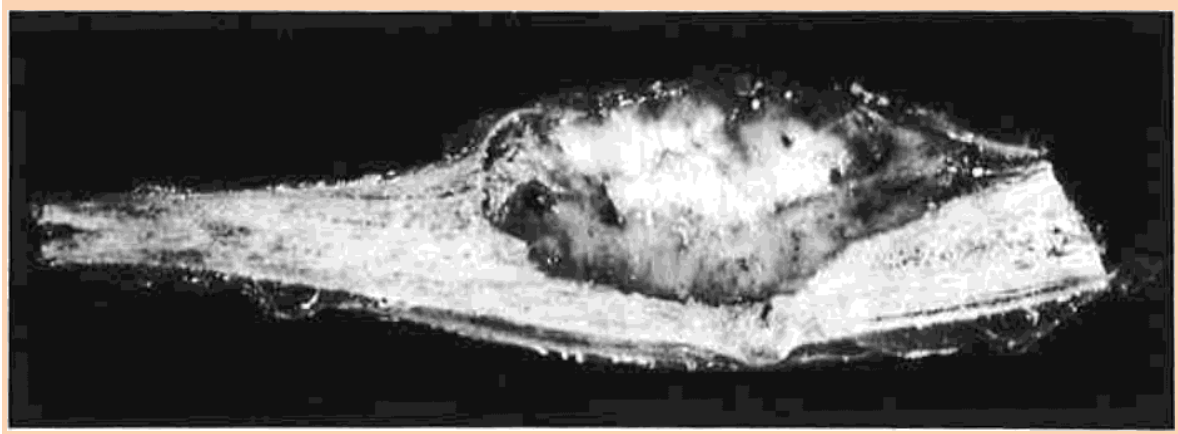

Fig. 83. Macroscopic view of a section of resected hone with osteoblastoma (10-year-old female patient).

The majority of the tumor tissue is centrally located and contains numerous hemorrhages. The cortex has been resorbed (courtesy of Prof. E. Ueh/inger, Zürich).

toma is cellular osteoblastic lesional tissue containing ample immature osteoid and woven bone (fig. 84). This woven bone is directly produced by highly vascular connec- tive tissue and not by enchondral bone for-mation. The complete absence of cartilage is a very helpful feature since it allows one to distinguish this lesion from osteogenic sarco- ma. An abundance of multinucleated giant cells usually occurs in proximity to vascular channels, deposits of extravasated blood, immature osteoid or newly formed bone (fig. 85, 86). Whereas in osteoid osteoma a fairly regular histological structure, charac- terized by peripheral maturation ofthe nidus is seen, the 
immature osteoid and latticed bone seen in cases of genuine Osteoblastoma appear to be more randomly distributed [Schul:.:., 1980].

The greatest problern for the pathologist lies not in distinguishing Osteoblastoma from osteoid osteoma but rather in distinguishing between Osteoblastoma and intramedullary osteogenic sarcoma. In essence, osteoid os- teoma and osteoblastoma progressively replace the host bone along a solid, well- defined 'wall' of osteoclastic destruction, 
while osteogenic sarcoma advances along a

'permeative front' until osteoclasts have completely destroyed the host bone. In osteogenic sarcoma the woven bone and os- teoid can be seen to infiltrate the host lamel- lar bone marrow to a depth of several milli- meters or even centimeters along their advancing edges. As has been stated, the presence of cartilage precludes a diagnosis of osteoblastoma. However, one must be aware that it may be possible for osteoblas- toma to induce a pathological fracture, and that in such cases cartilage would automati- cally be produced by the nontumoraus bone. Most Osteoblastomas produce thick trabecu- lae ofimmature osteoid and woven hone with irregular, serrated horders. The area covered hy the stroma and that occupied by the os- seous trabeculae are more or less equal. The stroma contains numerous prominent capil- laries and osteoclasts. Although osteosarco- mas may produce hone formations of this type (fig. 87), the picture normally presented is one of focal or extensive areas of compact osteoid or poorly calcified woven bone with a 'tightly knit' or 'streamer' pattern in which prominent vessels arerare (fig. 88, 89). 


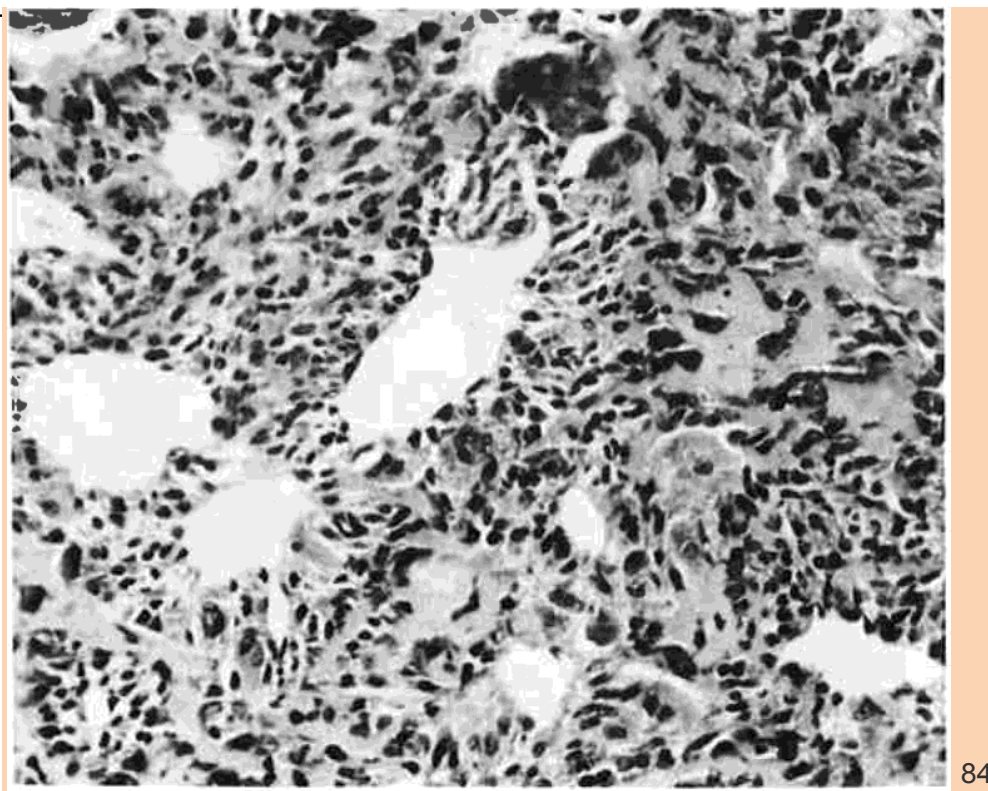

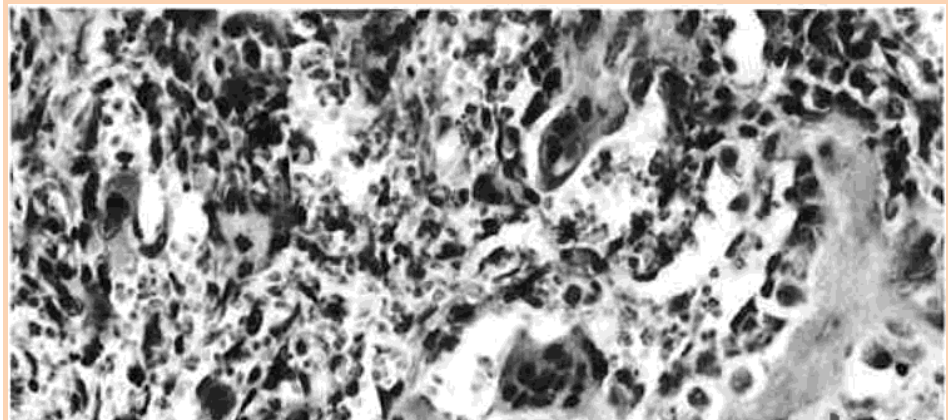

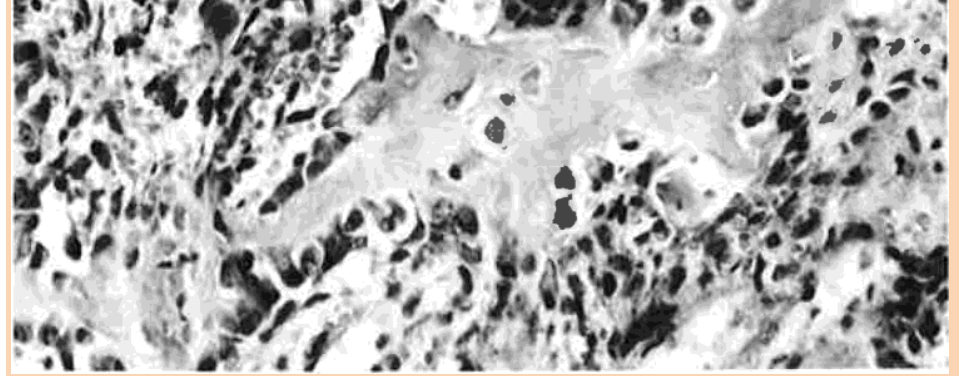

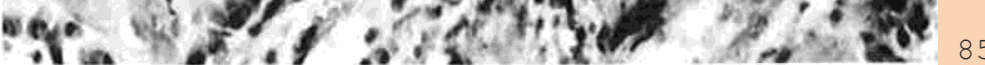

Fig. 84. Centrat area of an osteoblastoma. The stroma has a high capillary content. It also contains trabeculae of immature osteoid and !arge quantities of multinucleated giant cells. HE. $160 \mathrm{X}$. 
Fig. 85. The osseous trabeculae are weil differentiated. They are subject to simultaneous resorption (by

multinucleated osteoclasts) and bone apposition by numerous, !arge osteoblasts. Osteobiasts can be seen swim-

ming freely in the vicinity of these trabeculae. There are numerous hemorrhages in the stroma. HE. $250 \times$. 
fll

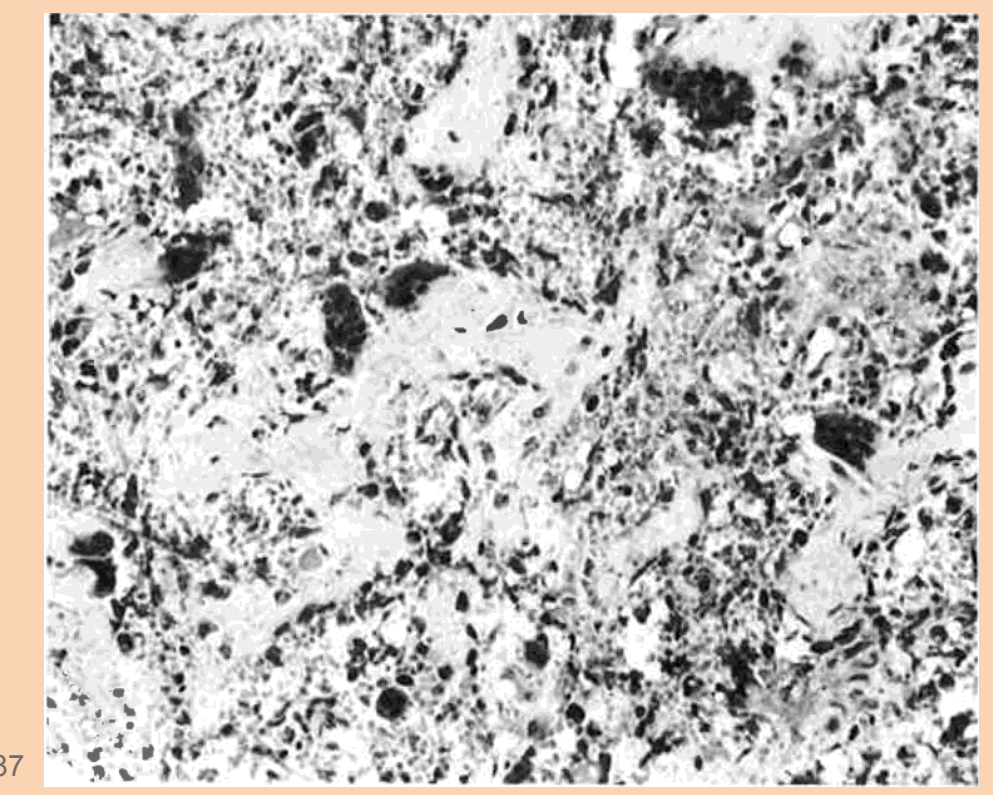

Fig. 86. Large numbers of multinucleated giant cells and fine strands of newly formed osteoid. HE. 250

X. Fig. 87. Material resected from a so-called 'teleangiectatic osteogenic sarcoma'. Multinucleated giant cells

and masses of tumoraus osteoid can both be seen in !arge numbers. It is extremely difficult to distinguish between this biopsy material and the kind one would normally associate with osteoblastoma. HE. $160 X$. 

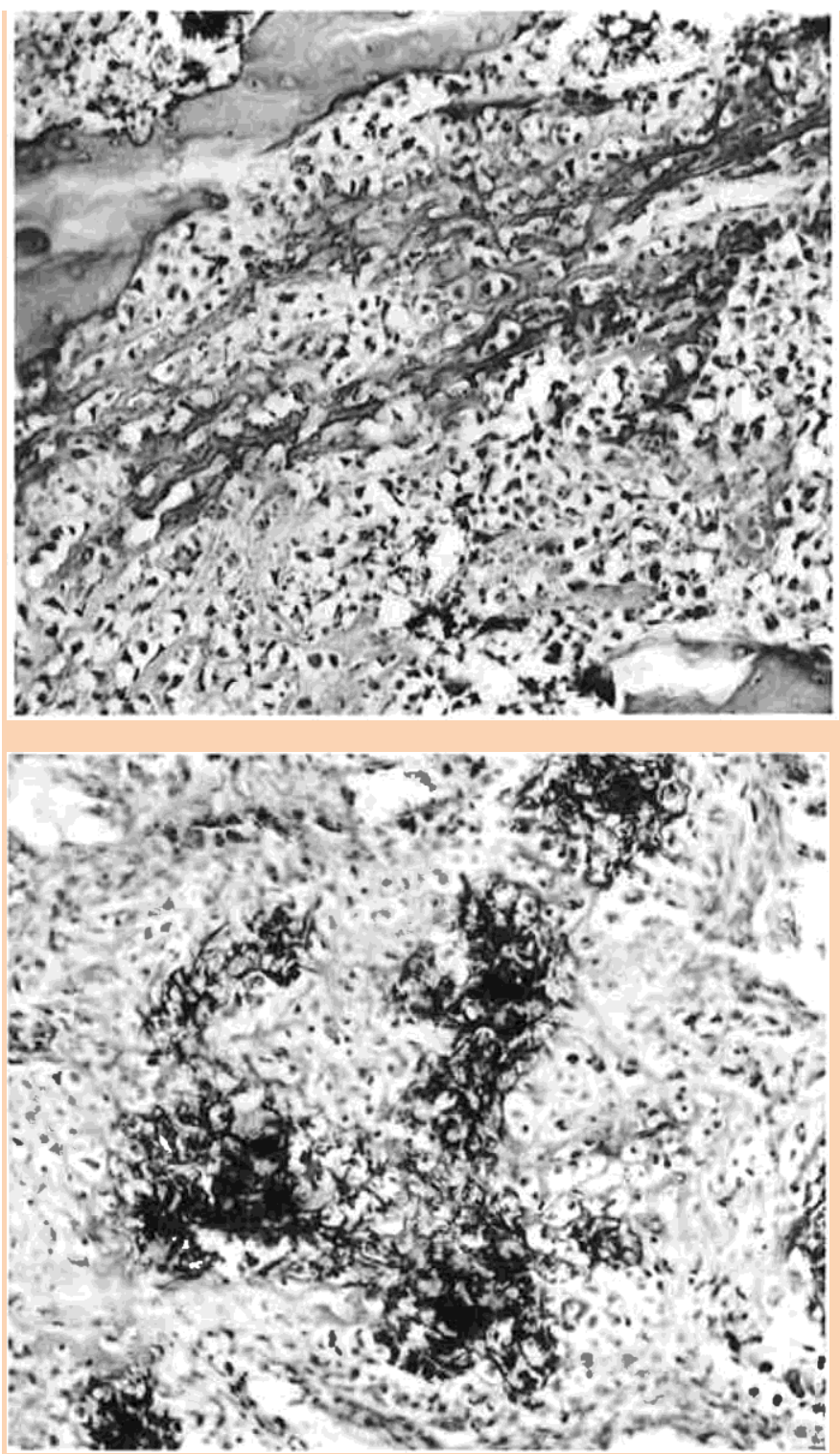

Fig. 88. Another biopsy slide taken from the same tumor as depicted in figure 87 . The tumorous mineralized structures have a characteristic coral-like shape. Note the numerous atypical osteoblasts. HE. $125 X$ 
Fig. 89. Osteogenic sarcoma with a low cell density featuring atypical osteoid in which threads of calcified

material are visible. HE. $160 \mathrm{X}$.

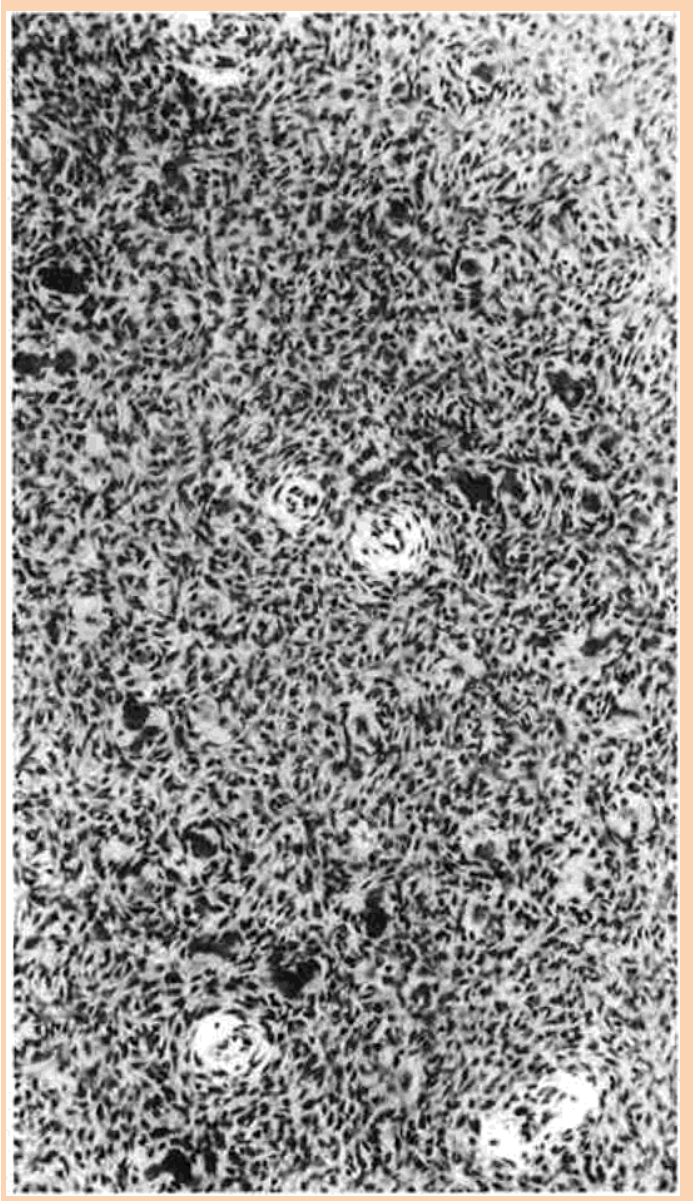

Fig. 90. Whirled tumorous stroma with a high cell content. Note the spherical intensely calcified foci of mineralization. HE. $100 \mathrm{X}$. 
In the affected areas, osteoid osteomas and Osteoblastomas both produce lesional tissue that is composed of immature osteoid and may also contain woven bone. Remnants of hast lamellar bone are rarely seen. Prominent osteoblastic rimming can be found in Osteo- blastoma and osteoid osteoma, though it rarely occurs in areas of malignant tumoraus bone formation. 
Fig.91. The stroma has a high cell content and the tumorous structures produced are spherical, intensel y mineralized and occasionally acellular. HE. 250 X.

In spite of the morphological differences between them, Schutz [1980] regards these three benign bone-producing tumors as cyto- genetically monophasal. Hesupports this view by pointing out that all the neoplastic transfor- mations which occur in these three types of tumor are of osteoblastic origin. He also das- sifies fibrous dysplasia as a cytogenetically monophasal condition. It is characteristic of 


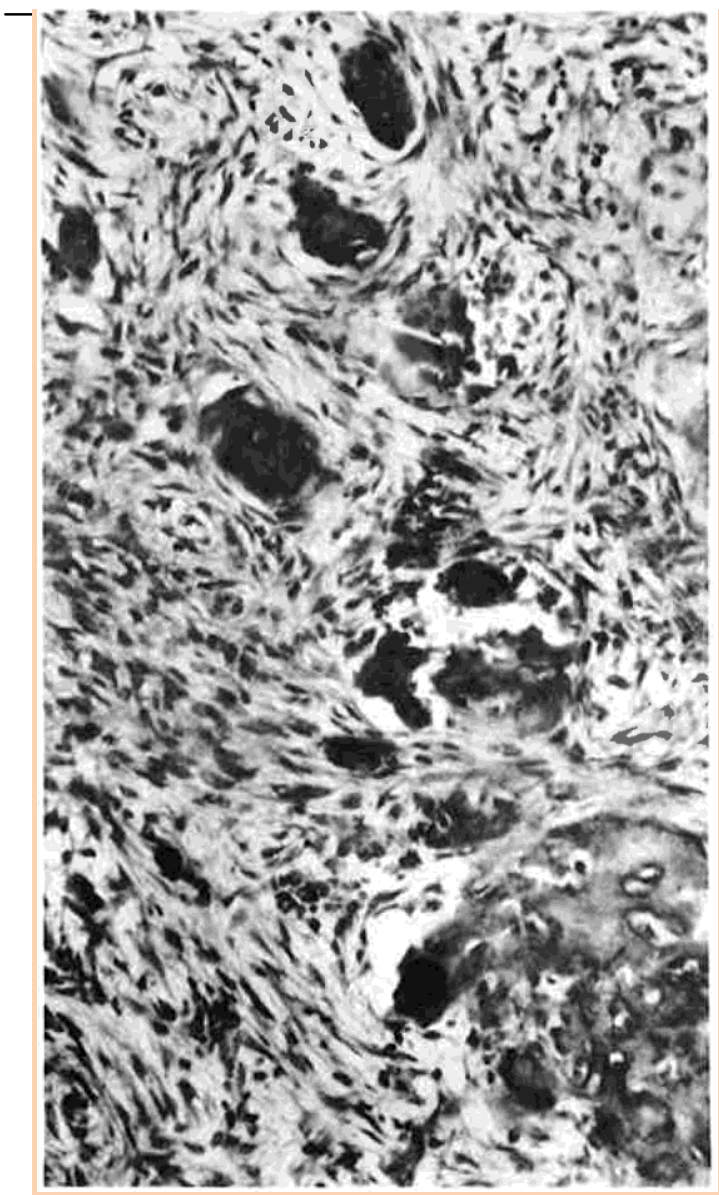

Fig. 92. The stroma has a high cell density and contains characteristically shaped spherical structures. The nuclei are slightly polymorphous. Resportion by multinucleated osteoclasts is in progress at the center of the lesion. HE. $200 \mathrm{X}$.

this last lesion that the immature osteoblasts (in stage III) develop into apolar Osteobiasts (stage IV). The reactive tissue occurring in fibrous dysplasia consists of fibroblasts and osteoclasts, some ofwhich are multinucleated giant cells. In osteoma, on the other hand, cell production is perfectly normal. The fact that practically all the cells found in cases of osteoma are groupearound extremely well- 
Fig. 93. Well-vascularized stroma containing acel- lular tumor tissue surrounded by osteoblasts and similar in appearance to osteoid. HE. $400 \mathrm{X}$.

defined, polarized osteoblasts and osteocytes can safely be regarded as sufficiently conclu- sive evidence that osteoblastic cell production in tumors ofthistype is in no way impaired. In cases of osteoma, it would appear that the pool of proliferating stage II cells (i.e. cells which still have the ability to divide mitotically) pro- duces a number of precursor cells which de- velop directly from stage II tostage V (polar- 


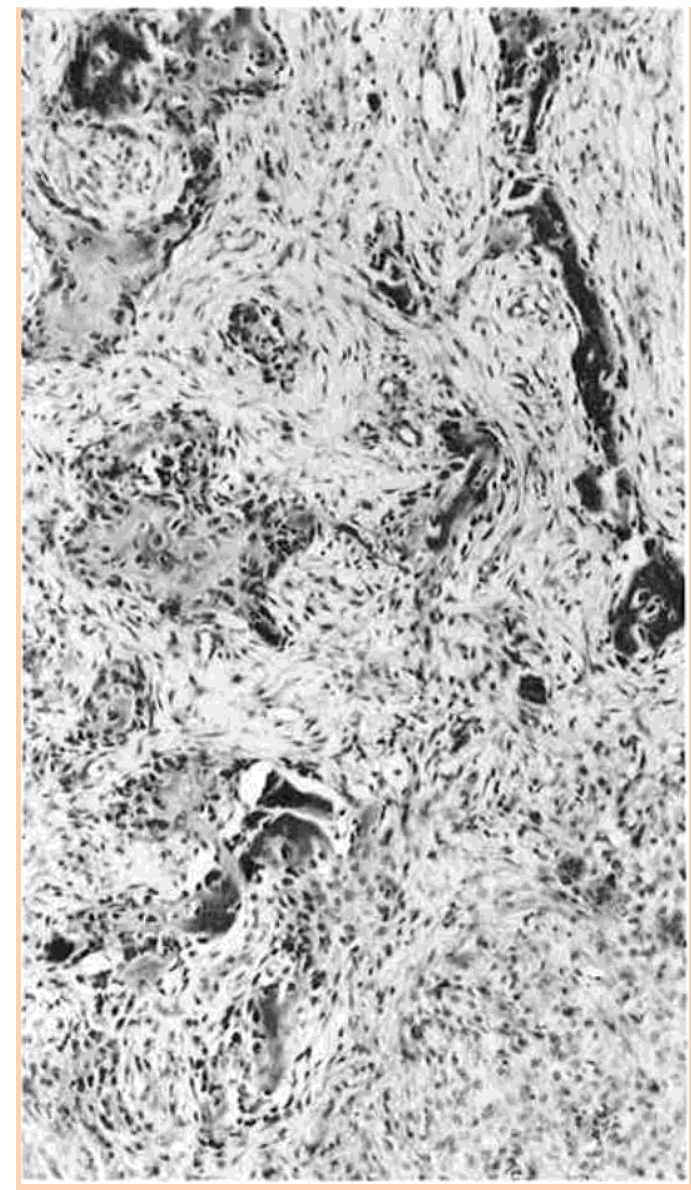

Fig. 94. The stroma is very loose and is well vascu- larized. It contains fine, delicately structured trabeculae of woven bone surrounded by numberous osteo- blasts. HE. $80 \mathrm{X}$.

ized osteoblasts), without passing through stages III or IV. In other words, they imme- diately become polarized osteoblasts without first having passed through the normal 'imma- ture' and 'apolar' phases [Schulz, 1980]. Os- teoblastoma and osteoid osteoma differ from 
osteoma in that the development ofthe major- ity oftheircells seems to have been arrested at a comparatively early stage of cytogenetic devel- 
Fig. 95. The stroma has few collagenaus fibers. Note the cells similar in appearance to Osteobiasts and the trabeculae of immature osteoid. HE. $230 \mathrm{X}$.

opment: in osteoma, increasing numbers of tumor cells develop first into preosteoblasts and then into mature osteoblasts, which have the ability to produce fibrous osteoid and to mineralize the bone matrix. As the tumor cells develop, they shift from the nidus towards the periphery, so that the most mature cells are always peripherally located. As far as can be determined from the ultrastructural evidence 


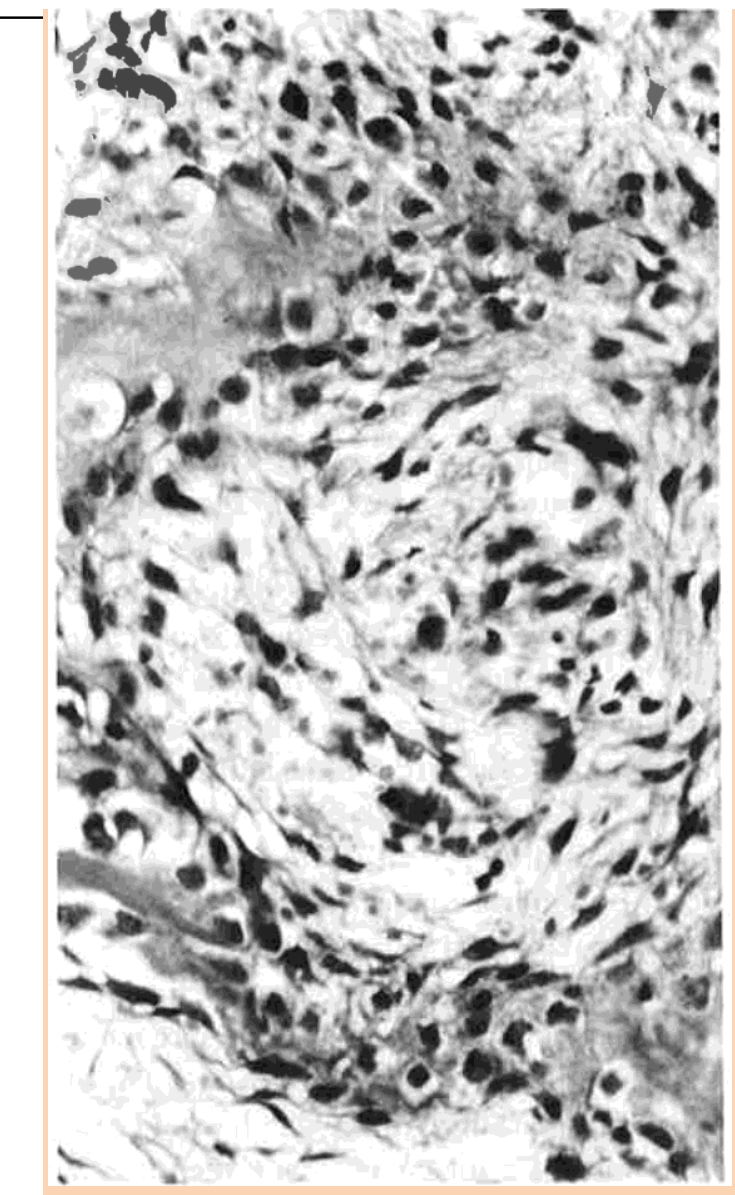

Fig. 96. Consolidated stroma cells in which osteoid has been produced at random . HE. $360 \mathrm{X}$.

available [Schutz, 1980], highly defined osteo- blasts capable of producing lamellar bone, such as occur in cases of osteoma, are not present in cases ofosteoid osteoma. As Steiner [1976] points out, the cells found in Osteoblas- tomaare extremely similar to those occurring in osteoid osteoma, a fact which makes differ- ential diagnosis of these two lesions particu- larly difficult. Differences can, however, be 
Fig. 97. Stroma cells, whose appearance is similar tothat of osteoblasts, viewed under intense magnifica- tion. In this picture they are in the process of consoli- dating. HE. $400 \mathrm{X}$.

detected under the e1ectron microscope, par- ticularly in the quantitative distribution of mature tumor cells in the two types oflesion. In osteoid osteoma, the mature cells tend to be concentrated around the periphery of the tu- mor and apolar Osteobiasts frequently occur there. In osteoblastoma, on the other hand, these more mature types of tumor cells are located exclusively in little is1ets of fibrous

osteoid which are found throughout the stroma.

In the case material drawn from the files of our clinic there are a total of 26 cases of bone-producing tumors whose characteristics do not conform to those of any of bonepro- ducing tumoraus entities described in the lit- erature. A consideration of their histological features suggested that it would be appro- priate to divide them into two distinct subca- tegories. The !arger of the two groups thus created contains 17 cases, representative ar- eas of which can be seen in figures 90-93. These 1esions are characterized by whirled stroma with a high osteablast content, in which concentric circular layers oftrabecu1ae of woven hone similar in appearance to psammoma bodies can be seen.

Only rarely do the trabeculae in the nine cases in the second group (fig.94-97) resem- ble the psammoma-like bodies described above; most are composed of woven hone and are thin and forked. The stroma is al- most entirely cellular in composition and contains very few collagenaus fibers. A care- ful examination of their morphological and functional characteristics clearly shows that the cells in the stroma of both categories of tumor are osteoblastic. The histology and case history of these 
tumors was studied in detail and the results of this examination, which are presented in detail (p. 128), can be summarized as follows: (1) These tumors are very aggressive and have a marked tendency to recur. They should therefore be distin- guished from certain other types of tumor which occur in the tooth-bearing regions of the jaw only and will be discussed in the next chapter. (2) Neither in the literature nor in the case material used for the present study are there any cases of tumors of this kind occurring in any other locations than the 
cranio-facial and jawbones. (3) Both histo- logical subcategories ofthese have been seen to occur not only in the jawbones, but also in the region of the paranasal cavities. Only lesions of the type belanging to the larger group occurred in the roof ofthe skull. Their incidence is therefore not restricted to tooth- bearing regions of the maxillo-facial bones. (4) In all the cases of both the conditions on file at our clinic, the lesion was first detected when the patient was aged 22 or less.

It emerges from point 3 that these tumors occur in preformed desmal bones whose main functional purpose is bone tissue appo- sition and which can therefore form mature new bone without going through a prelimi- nary phase of cartilaginous production. Since all 26 tumors occurred in desmal preformed bones, it seems reasonable to assume that tumorsoftbis type can, by their very nature, occur only in those locations.

The next logical step would of course be to attempt to define their cytogenetic character- istics. To do so with anything approaching total certainty would require exhaustive ul- trastructural examinations which would have little hope of being conclusive if the material examined were paraffin embedded. Since none ofthe case material used for the present study was fresh, it seemed extremely doubt- ful whether the reliability of the conclusions such an examination would produce would be in any way commensurate with the effort they would require. Furthermore, since the cytogenetic characteristics of these tumors would in any case have little ifany bearing on their diagnosis or therapy, and since the ra- diological, histological and clinical data al- ready available is sufficient to define these tumors as characteristic pathological entities, it was decided not to subject the material to ultrastructural examination. The histological 
characteristics of these two entities are de-scribed in detail (p. 144 and 175) and need not therefore be discussed at length here. It can however be mentioned at this stage that in view of the characteristic aggressivity of these tumors, their high rate of recurrence, the fact that the trabeculae are composed exclusively of woven bone and the complete absence of lamellar bone formation, it seems more than reasonable to assume that the osteoblasts occurring in both types of tumor are immature. The concept of a bone tumor originating in immature osteoblastic cells is of course hypothetical. It is, however, rele- vant to point out that such an assumption would correspond to the hypothesis which Schutz [1980] arrived at having subjected numerous bone-producing tumors to ultra- structural examination.

Once it had been established that these 17 tumors were histologically and biologically identical, a systematic review of the clinical, radiological and histological data pertaining to all the available published cases of benign bone-producing tumors occurring in the des- mal preformed bones ofthe maxillofacial and cranial areas was undertaken with a view to compiling a list of other cases which were his- tologically and biologically identical. It was of course appreciated that, since neither the 1971 WHO classification nor any earlier at- lases or registries describe entities of this type, the terminology alone would be of little assistance in unearthing such cases. This re- view of the literature produced a total of 69 cases of tumors of this type, details of which are given in table XVII. A total of 86 tumors (69 from the literature and 17 from the files of our clinic), which were histologically and biologically identical could therefore be con- sidered. The next task was to attempt to find a single description defining a specific type of 
tumor cell or tumorous product which would fit them all. Only in this way could the findings produced be of any real practical or ther- apeutical use.

As table XVII shows, an immense variety

of diagnoses have been returned. The tumor- aus tissue produced has been variously de- scribed as 'psammous bodies', 'osteoid', 'ce- mentum', 'woven bone', and 'fibrous tissue'. There is little unanimity on the question of the cytogenic nature of these tumors; some authors describe them as 'psammous fibro- ma' or 'psammoma', others prefer 'psammo- osteoid fibroma', 'fibrous dysplasia' or 'ce- mentifying fibroma', while yet others have opted for 'juvenile ossifying fibroma' or else pronounced a verdict of 'ossifying fibroma', as in the case ofthe ultrastructural study car- ried out by Damjanov et al. [1978). From the above it will have emerged that some ofthese terms postulate lesions in which the sup-posed mother cell and its product are not identical. It is a universally accepted princi- ple of embryology that each of the three tis- sue-producing cells (osteoblasts, fibroblasts and cementoblasts) produces its own specific product (osteoid, collagenaus fiber and ce- mentum, respectively). Acceptance of some of the diagnoses presented in table XVII would require this principle to be refuted. Even if one were prepared to take such a step, one would still be unable to define a set of pathogenetic characteristics which would fit all the cases mentioned, or to define one sin-gle type of cellular product (osteoid, collage- nous fiber or cementum) which was specific to them all.

The difficulties attendant upon accep- tance of the hypothesis that specific types of mother cell might produce an unspecific cel- lular product are quite obviously insurmountable. There is, however, another possi- 
Author(s)

Year

Age

Sex

Site

Original diagnosis

I

Moser

1899

16

f

sinus frontalis

Sarkom

2

Krogius

1902

29

m

sinus frontalis

Sarkom

\section{VanEicken}

1922

16

ethmoid

Psammom

4

Wiegmann

1929

16

ethmoid

Psammom 
49

m

sinus frontalis

Osteoidoma

\section{Shaheen}

1931

12

m

maxilla

Psammoma

7

Tschipper

1931

23

maxilla

psammöses Fibrom

Reiche/

1934

14

nose, ethmoid

Sarcoma psammosum

Arons

1937

11

m

sinus maxillaris

ossifying libroma

10

Kanewski

1937 
ethmoid

\section{Psammom}

11

Van Eicken and Schürmann

1937

47

m

shius frontalis

wenig ausgereiftes Fibroosteom

12

Benjamins

1938

19

orbit

Osteoid-Fibrom mit atypischen Verkalkungen

13

Dijkstra

1938

20

m

sinus frontalis

\section{Endothelioma psammosum}

14

Baizer

1939/4

$0 \quad 16$

sinus frontalis

verkalktes Fibrom

15

Baizer

$1939 / 4$

$0 \quad 19$

m

sinus frontalis

verkalktes Fibrom 
Fry and de Long

1941

32

m

sinus front. (orbit)

\section{Psammoma}

17

Woodrz;fJ

1945

13

sinus front. (ethmoid)

ossifying fibroma

18

Willis

1948

26

m

maxilla

libroma

19

Willis

1948

temporal region

hamartoma

20

Gögl

1949

m

sinus frontalis

Psammo-Osteoid Fibrom

21

Gögl

1949 
ethmoid

Psammo-Osteoid Fibrom

22

Sonesson

1950

212

mandible

libro-osteoma

23

King and Hayes

1951

21

m

orbit

fibrous dysplasia

24

King and Hayes

1952

27

m

orbit

librous dysplasia

25

Dintenfass et al.

1952

25

ethmoid

ossifying fibroma

26

Brunner

1952 
fibrous dysplasia

(ossifying libroma)

27

Skolnik and Fornatto

1955

28

maxilla

ossifying fibroma

28

Skolnik and Fornallo

1955

m

maxilla

ossifying fibroma

29

Skolnik and Fornatto

1955

m

maxilla

cystically degenerated 
ossifying libroma

30

Skolnik and Fornatto

1955

28

m

sinus frontalis

cystic ossifying fibroma

31

Kleinsasserand Albrecht

1957

12

sinus frontalis

\section{Osteoid-Fibrom}

32

Kleinsasser

1958

13

sinus frontalis

\section{Osteoid-Fibrom}

33

Rumpf

1958

10

m

ethmoid

psammöses Meningeom

34

Dejean et al.

1959

13

m 
sinus frontalis

Meningeom

35

Harpman

1960

12

orbit

calcifying libroma

36

Rossi and Cherubim.

1961

m

orbit

ossifying libroma

37

Mincione et al.

1964

12

m

ethmoid

libroma ossificante

(cementolibroma)

38

Gass

1965 
orbit

fibrous dysplasia

39

Gass

1965

$\mathrm{m}$

orbit

librous dysplasia

40

Young and Putney

1968

14

ethmoid, maxilla

ossifying fibroma

41

Young and Putney

1968

15

$\mathrm{m}$

maxilla

ossifying fibroma

42

Young and Putney

1968

12

sinus front. ethmoid

ossifying libroma

43

Young and Putney

1968

21

sinus frontalis

ossifying fibroma 
44

Katzer

1969

37

ethmoid

Psammo-Osteoid-Fibrom

Table XVII (continued)

Case Author(s)

$45 \quad$ Katzer

Fibrom

$\begin{array}{lc}\text { - } 46 & \text { Lehrer } \\ -47 & \text { Lehrer } \\ -48 & \text { Scoll et al. } \\ -49 & \text { Darsie and Kenan } \\ - & \text { Darsil' and Kenem } \\ & \\ & \text { Darsie and Kenan }\end{array}$

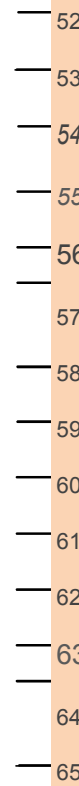

\section{Lichtenstein}

Prabhakar et $\mathrm{nl}$.

Ellis and Wallers

Oli॰-er

1973

Dehner

Dehner 1973

DeJmer

Dehner

Fu and Perzin

Fu and Perzin

Fu and Perzln

Gay et al.

Krausen et al.

Gutjahr et nl,

Year

Age

Sex

Site

Original diagnosis

1969

28

parietal

Psammo-Osteoid-

$\begin{array}{lllll}1969 & 20 & \text { m } & \text { orbit } \\ 1969 & \text { I I } & \text { m } & \text { orbll }\end{array}$

$1971 \quad 22 \quad f$

ethmold, sphenoid, antrum max.

Meningeom

$1971 \quad 15 \quad m \quad$ orbit, ethmoid

ossifying fibroma SO

1971

19

m

ethmoid, sphenoid, orbit

ossifying fibroma SI

1971

34

r

sinus frontalis

ossifying fibroma

19729

$1972 \quad 21 \quad m$

temporal region

osteoblastoma

frontal region

osteoid osteoma

1972

17

m

maxilla

aneurysmal cyst with cementifying fibroma

20

mandible aneurysmal cyst with fibrous dysplasia

$$
\text { m }
$$

antrum max

cementifying fibroma

antrum max.

$\begin{array}{rr}1973 & 6 \\ 1973 & \text { II } \\ 1974 & 7 \\ 1974 & 9 \\ 1974 & 15 \\ 1975 & 16 \\ & \end{array}$

cementifying libroma in an aneurysmal bone cyst

f antrum max.

antrurn max.

ethmoid, orbit

ethmoid, sphenoid, orbit

sinus frontalis

cthmoid, sinus max., nose cementifying fibroma

cementifying fibroma

young ossifying libromn young ossifying fibroma young ossifying fibroma ossifying fibroma

ethmoid aggressive ce.menl(\}-ossifying fibroma 
Examination of the Case Material and Conclusions

-66 Damjanov et al.

$-67$

Reale et al. 1978

Seitz et al.

Sweet et al.

$-69$

7 Cases from the Zürich University Hospital

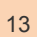

10

12

ethmoid

frontal
13

juvenile ossifying fibroma

ossifying fibroma

cementifying fibroma

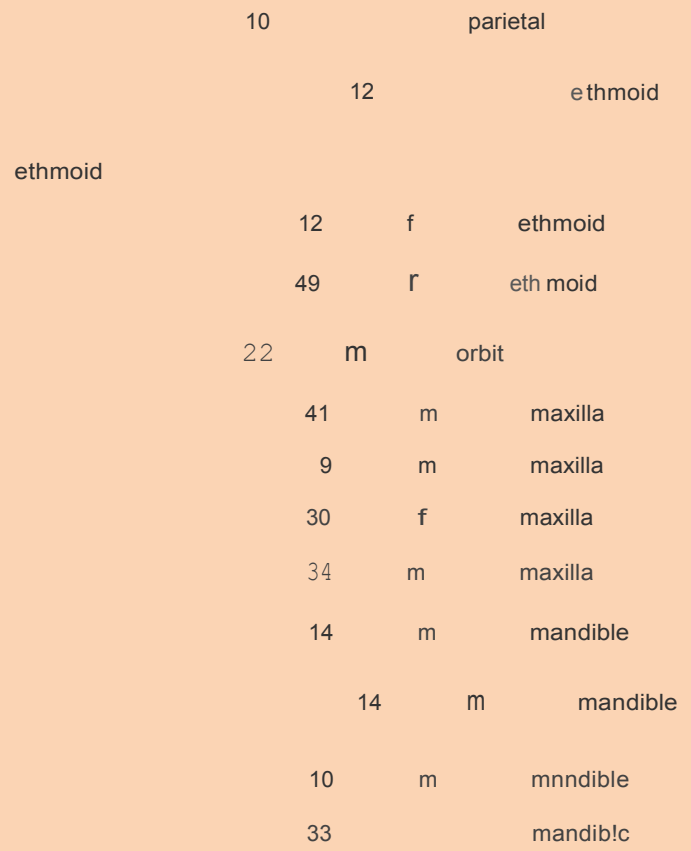

bility put forward in the literature; faced with what they saw as an 'aggressive cementoossifying fibroma' occurring in the ethmoid region, Krausen et al. [1 977] suggested that the condition might have been caused by an 'ectopic periodontal membrane in the eth-moid region'. Such a hypothesis is theoreti- cally acceptable in the case which these au-thors describe, and indeed, Shanmugarat- nam [1978] classifies a tumor of this type occurring in the maxillary sinus as 'cemen- tifying'. Quite a !arge number of these cases are in fact located in the 
tooth-bearing re-gions and have been classified as cementum- producing. The problem, however, lies in the fact that, since all 86 cases are biologically and histologically similar, one would have to postulate one single type of cellular product for all of them. Although cementum cannot be ruled out on a priori grounds in cases where the tumors occur in the tooth-bearing regions, and although it is theoretically acceptable as a very rare ectopic phenomenon in the case described by Krausen et al. [1977], acceptance ofit as the common cellular prod- uct for all tumors of this type would require an immeasurably high incidence of ectopy, so high indeed that it would exceed normally localized cases by a ratio of $11: 3$. This ectopic process would also have to be able to trans- pose tissue to rather remote sites, as a case described by Seitz et al. [1980], in which 'ce- menticles' are described as occurring in the parietal bone, shows. Little, if anything, has been said about the second histological subcategory to which 9 of the 26 cases from the files of our clinic were assigned. This is because their biological characteristics are the same as those of the !arger group of 17 cases and because they affect the same age group. In other words, it is only from a histological point of view that 
- they differ from the tumors in the !arger group; their specific histological characteris- tics are that their stroma is much looser, that their trabeculae are slender and forked as opposed to spheroid and that they contain far fewer collagenaus fibers. In evolving a de-scription capable of being applied to all 26 cases, it seems ofparamount importance that their clearly observable radiological and his- tological characteristics should be taken into account, so that the term itselfwill be imme- diately evocative of the essential characteris- tics of the entity it describes.

Because both tumor types are of osteo-

blastic origin and occur in the maxillofacial and cranial regions of the skeleton only, it seems appropriate to term them 'desmo- osteoblastomas'. To differentiale between the two subcategories it was necessary to find some term which drew attention to their mu- tually distinctive features. The term 'psam- mous desmo-osteoblastoma' seems particu- larly suitable for the first group (comprising

17 cases), since it refers to the tumor's spe- cific product, and because many of the au- thors cited in table XVII appear to have been struck by its characteristic psammous ap- pearance, since they either described it as 'psammous' or 'meningioma'. For the second subcategory, the term "trabecular desmo- osteoblastoma' has been chosen so that atten- tion could be drawn to the slender, forked shape of the soft trabeculae of woven hone which characterize tumors of this type.

Tumors of Cementoblastic Origin

Benign cementoblastoma is the only ge- nuine monophasal cementum-producing tumor which can occur and it has already been described in detail (p. 28). 


\section{Tumors of Fibroblastic Origin}

Recent literature refers only very rarely to cases of tumors which consist exclusively of fibroblasts and collagenaus fibers (i.e. ge- nuine fibromas) occurring in the maxillofa- cial bones (table XVIII). It is significant that all seven recently described cases have been localized in the mandible. The case material used for the present study does not include 
Table XVIII. Published cases of central (genuine)

fibroma of the jawbones

Case Author(s) Year Age Location

Goh $1954 \quad 4$ mandible

$2 \quad$ Mark 195518 mandible

3 Rosen and Greenjie/d $1963 \quad 8$ mandible

$4 \quad$ Marlette and Gerhard $1968 \quad 45$ mandible

$5 \quad$ Hanley et al. 197167 mandible

$6 \quad$ Martis and Karakasis 197230 mandible

$7 \quad$ Ferguson1974 5 mandible

any cases of benign, purely fibrous tumors of

this type. A considerably greater number of cases of fibroma occurring in the jawbones are described in earlier literature [Blaue/,

1903; Uyeno, 1909; Müller, 1920]. The last of these authors published a review of 16

cases of centrally located fibroma reported prior to

1920,5 of which occurred in the maxilla and

11 in the mandible. He stated that the total absence of any processes of

mineralization within the tumor itselfwas a specific charac- teristic of fibroma. He regarded centrally lo- cated fibromas as 'odontogenic tumors' origi- nating in immature tooth germs. It would seem prudent to make any diagnosis of odon- togenic fibroma subject to the possibility of desmoplastic fibroma having first been ruled out. 
Tumors of Multiple Cytogenic Origin

In addition to the three different cytogenic types oftumorsjust described, it is quite possible for tumors to occur in the tooth-bearing regions of the skeleton which have two or even three different mother cells (i.e. fibro- blasts, Osteobiasts and cementoblasts as de-scribed in chapter 3). It would be normal to expect such tumors to produce more than one type of cellular product. The mother cells of these tumors would obviously have to 
- originate in polyvalent tissue (i.e. tissue con-

taining cells of various types, each of which has the ability to produce a different type of cell product). The only region ofthe maxillo- facial skeleton in which polyvalent tissue ca- pable ofproducing both bone and cerneuturn is found is the periodontal mesenchyme. It is here that tumors producing both bone and cementum must therefore logically be as- sumed to have their orthogenesis. Tumors whose cellular product consists wholly or in part of cementicles must always be differen- tiated histologically from the two types of desmo-osteoblastoma described (p. 128), since these can also occur in the tooth-bear- ing regions and are superficially similar in appearance to cementum-producing tumors.

The case material used for the present study contains a total of 15 tumors of multiple cytogenic origin, all ofwhich are localized in the tooth-bearing regions of the jawbones. They can be differentiated from the desmo-osteoblastomas referred to above by their slow growth, their occurrence in patients of advanced age and the fact that they do not appear to recur. They also have specific his- tological characteristics (fig.98-101) which are discussed and illustrated on page 200. 


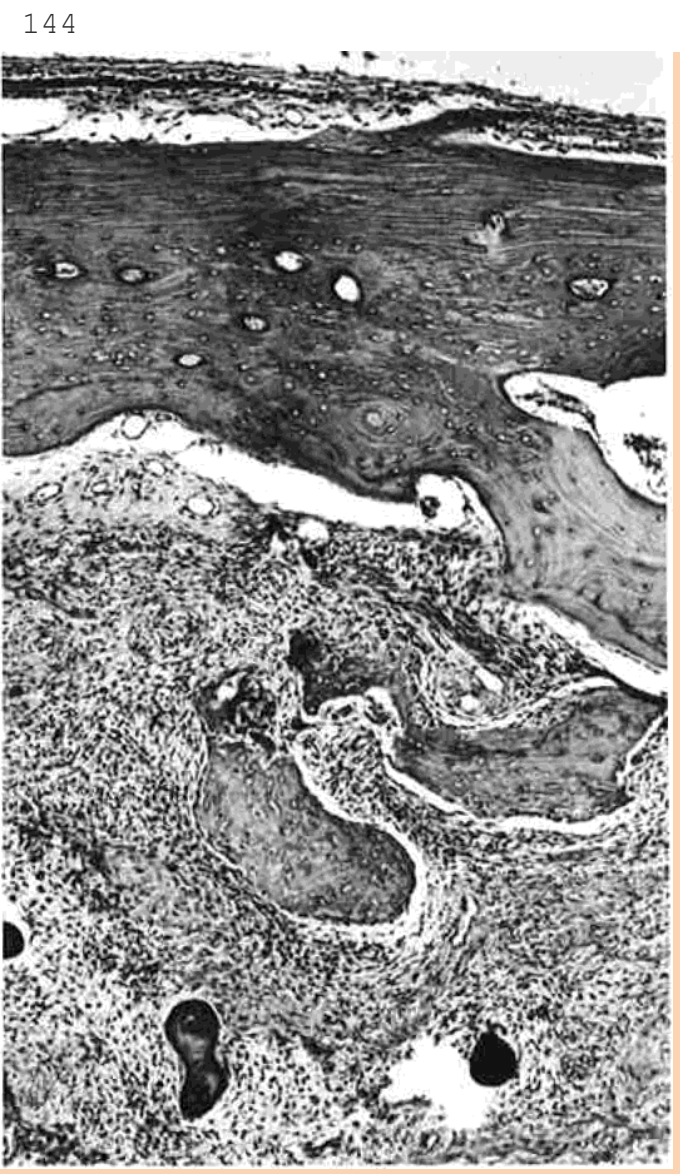

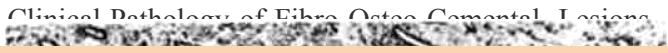

Fig. 98. The tumor has extended into the subcorti- cal region. The tumor tissue has a high cell content. Although they are broad and somewhat cumber- somely shaped, the osseous trabeculae are of lamellar composition. Note also the spheroid, layered, in- tensely calcified cementicles. HE. $40 \mathrm{X}$.

Some authors [Hamner et al., 1968; Wal- dran, 1970; Dehner, 1973; Ackerman and Rosai, 1974] take the view that it is the pres- ence of cementicles which gives these tumors their specific character, and therefore define them as 'cementifying fibroma'. Abrams and Me/rose [1975] are more sceptical. They 
-Fig. 99. Material excised from the central area of the tumor. The stroma contains many collagenaus fibers. Cementicles and curved trabeculae ofbone can also be seen. HE. 40 X.

point out that it is rarely possible, using con- ventional microscopic techniques, to distinguish between bone and cementum, and therefore classify tumors of this type as part of the !arger 'ossifying fibroma' group. It is because of this immense similarity between cementum and bone that some authors [Hamner et al., 1968; Dehner, 1973] have also described the tumor as 'cemento-ossify- ing fibroma'.

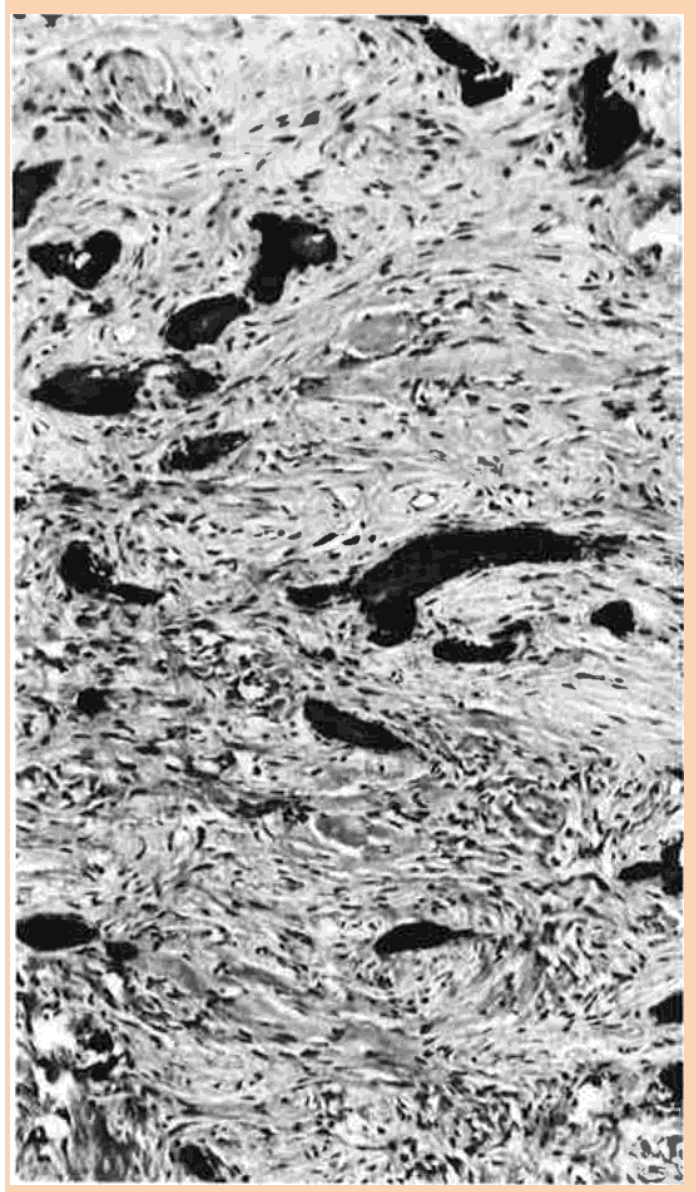


Fig. 100. Tumor tissue viewed under greater mag- nification can clearly be seen to be beaded and intensely calcified. HE. $100 \mathrm{X}$.

While it is undoubtedly true that the con- siderable variety of terminology used in this area is a direct result of the difficulties atten- dant upon a differentiation between bone and cementum, it must also be recognized that all the terms quoted above have one feature in common, namely that each constitutes an attempt to define a tumor by isolating the predominant type of tumorous cell tissue present and then naming the tumor after it. 
Fig. 101. Characteristic trabeculae of bone pro- duced by the tumor. Note the resorption in progress at the center. HE. $100 \mathrm{X}$.

As things stand at present, the terminology used causes considerable interdisciplinary confusion. Furthermore, it is difficult to see how, in the present state of knowledge, cementum and bone could be distinguished from each other without the aid of sparsely available and highly sophisticated equip-ment. In these circumstances, it would seem worthwhile to devote some time to consid- ering the following: (1) What the precise cel-

lular characteristics of cementum are as far as is known today. (2) How cementum can be distinguished from bone. (3) Whether the clarity that such a distinction might bring to terminology of the type currently used (i.e. that which is based on which particular type of tumorous tissue is seen to predominate) would be ofvalue to those whose task it is to diagnose and treat lesions of this type.

Sehröder [1976] describes the ultrastructural char-acteristics of human cementum. He differentiales between three different types: (I) cementum containing neither collagenaus fibrillae nor cementocytes; (2) cementum containing collagenaus fibrillae but no cementocytes, and (3) cementum containing both cementocytes and collagenaus fibrillae.

AsSehröder [1976] sees it, some cementoblasts pro- duce a basic cementoblastic product which is the fundamental component ofall cementum, that is to say that it contains neither collagenaus fibrillae nor cementocytes. Other cementoblasts, which also produce this basic acellularproduct, combine the acellularcementum they produce with the collagenaus fibrillae produced by fibroblasts thus forming a type 
of cementum which is composed of !arge numbers of coll genous fibrillae, some ofwhich are grouped into bundles, but which con- tains no cementocytes. Sehröder [1976] refers to this second type of cementum as acellular-fibrillar cemen- tum. The third type, cellular-fibrillar cementum, con- tains both cementocytes and !arge numbers of collage- naus fibrillae, many ofwhich are grouped tagether into bundles. This type ofcementum is also a common prod- uct of cementoblasts and fibroblasts, but it differs from the second type mentioned above in that it is kept alive by the cementoblasts. Sehröder [1976] states that the existence ofthe second type ofcementum (the acellular- fibrillar variety) can be observed with complete cer- tainty only under the electron microscope, since histo- chemical and conventional microscopic techniques do not allow it tobe distinguished from the basic acellular- afibrillar type of cementum. He considers 'cementicles' as spherical bodies composed of concentric shells of acellularcementum which can measure up to $0.2 \mathrm{~mm}$ in diameter. He states that they originale either inside the reticule ofthe tooth or in the desmodontal tissue and are probably formed from degenerated epithelial cell re- 
mains, particles ofthrombosed blood vessels or degen-

erated elements of connective tissue.

Since present conventional microscopic tech-niques do not make it possible to distinguish between these three types of cellular product, it therefore fol- lows that they would be insufficient to show whether a particular group of hard substance bodies occurring in a tumor were genuine cementicles, which according to Sehröder [1976] would have to be composed of acellu- lar-fibrillar cementum exclusively, or trabeculae of bone produced by the tumor. In these circumstances it would seem inappropriate to allow the presence of spherical structures, which might or might not be 'ce- menticles', to influence a diagnosis of a tumor located in the jawbones.

Although the differences between bone and ce-mentum are minimal, they can reasonably be supposed to be somewhat greater than those between the three different types of cementum as described by Sehröder [1976]. Mjör and Fejerskov [1979] state that the basic substance out of which all mineralized tissue is formed is 'a calcium phosphate salt which in com-posltwn approximates calcium hydroxyapatite $\mathrm{Ca}_{10}\left(\mathrm{PO}_{4}\right) 6(\mathrm{OH})_{2}$. Sehröder [1976) gives details ofthe results obtained from a chemical analysis of enamel,

dentin, cementum and bone from which it emerges that both in terms of mass and volume the relative proportians of mineralized component, organic ma- trix and water found in bone barely differ from those found in cementum.

Aoba et al. [l 978] descri be a physicochemical exam-

ination they carried out ofa case of cementifying fibroma in the mandible using X-ray diffraction analysis and thermogra vimetric and differential thermal analyses. In their specimens, they found 'masses ofacellu1arcemen- tum-like tissues' at the center of the tumor, while the periphery was discovered to consist of'cementicle-like tissues'. X-ray broadeninglineanalysis revealed that the crystallinityofthecalcium hydroxyapatite in thecemen- tum-like tissue was higher than that ofthe apatitein the cementicle-like tissue and lower than that ofbone apa- tite (all three types of hard substance being obtained from the same patient). Thermogravimetrie and differ- ential thermal analyses also enabled them to establish that the minerat (ash) value ofthe cementum-like tissue was 'slightly higher' than that of bone. As Mjör and Fejersko1' [1979] point out. under nonpathological con- ditions the two tissues do differ in one important and easily verifiable respect, namely that bone is vascular-ized while cementum is avascular. 
Those who regard it as being of para- mount importance to know that one or other type of tissue predominates in a tumor will doubtless frequently have had occasion to regret that such a convenient distinction does not apply to lesional tissue also. 1t is cur- rently common practice to define a tumor according to which particular component predominates in the biopsy material exam- ined. A consideration of the biopsies taken from patients with benign tumors presenting multiple cytogenic characteristics who were treated in our clinic shows that the prognosis was in no way affected by which particular type of tumor tissue predominated (cemen- tum-like, bone-like or fibrous) in any given biopsy specimen. The truth of this is further emphasized by that the mineralization pat- tern often varied drastically from slide to slide of the same biopsy material.

The variations observed between the mineralization patterns of different slides from the same biopsy goes some way to explain why such a plethora ofterms as 'ossifying fibroma', 'osteofibroma', 'fibro-osteoma', 'cementofibroma', 'cementifying fibroma' and even 'ce- mento-ossifying fibroma', not to mention all eight types described by Panders [1970], are so frequently encountered in the literature. Since which ofthese terms happenstobe employed is entirely dependent on the particular part of the tumor from which biopsy material was excised, they are in fact totally arbitrary and can therefore cause considerable interdisci- plinary confusion. It would be generally ad- vantageous if definitions of this kind were abandoned in favor ofa simpler form oftermi- no1ogy which had a greater bearing on the tumors' prognoses and the types of therapy which they require. Such a step becomes particularly desirable when one considers that all the so-called 'entities' just cited are in fact 
- radiologically and clinically identical, but do, on the other hand, differ from the two forms of desmo-osteoblastoma mentioned earlier. Once one accepts that all the various terms mentioned above in fact refer to the same enti- ty, it is clear that what is required is a single clear term with which to describe it. Ifthe con- fusion now reigning in this area is tobe circum- vented, then the term chosen will obviously have to refer to some constantly observable feature which is common to all tumors of this type. Since this entity has only been observed in the periodontal region, and since it always contains a com bination offibrous, osseous and cemental tumor tissue, it seems reasonable to assume that its cytogenetic origins are to be found in the periodontal mesenchyme, since this is the only type of mesenchyme in the human body which can produce fibroblasts, osteoblasts and cementoblasts. The term 'peri- odontoma', which refers to the localization and the origin ofthis entity, would appear to meet the case more than adequately.

It is interesting to note that the literature

frequently refers to Hamneret al. [1968] as the first study to have recognized the periodontal membrane as the site where certain types of tumor have their orthogenesis [Waldran and Giansanti, 1973b]. Nimier, writing in the last century, appears to have assumed that tumors could originate in the periosteum ofthe tooth alveolae or in what he refers to as the 'ligament dentaire'. That at least is the impression con- veyed by Blaue! [1903] who quotes Nimier on this point. Blauel's [1903] own view isthat cer- tain types ofbenign tumors could originate in displaced tooth germs. Bömke [1939] wrote: 'In my opinion, the formation ofthese so-called cementicles is an indication that the orthogenesis of tumours (of this type) is in some way connected with the cementum-producing elements, i.e. the 
reticula ofthe teeth.' Herzog [1944] is clearly of the same opinion: 'Connective tissue tu- mours occurring in contiguous proximity to the teeth originate both in the mesenchymal tissue from which tooth pulp is formed - the so-called "peridontium" or "paradontium"- and the osteoclastic tissue which is formed when deciduous teeth are replaced by the per- manent teeth.'

The authors just cited all describe benign

tumors of periodontal origin which were cen- trally located. If one accepts that they origi- nate in the periodontal tissue, then it is logi- cal to assume that they can occur wherever there is periodantat tissue and that they are therefore unlikely to be restricted to central localizations. Since the possibility of their also occurring peripherally could not be ruled out on any logical grounds, it seemed neces- sary to carry out a systematic review of the literature and the case material used for the present study in order to discover whether any histologically identical tumoraus lesions had occurred in peripheral locations.

The case material used forthe present study

contains a total of 370 peripherally located lesions, i.e. lesions localized in the gingiva, drawnfrom thefiles ofourclinic between 1950 and 1980. It is interesting to note that in all370 cases the original clinical and histopatholog- ical diagnosis returned was 'epulis' in one ofits many forms (epulis granulomatosa. giant cell epulis, epulis fibromatosa or epulis featuring calcification and ossification).

As was mentioned on page 53 , all the biopsy material drawn from the files of our clinic was subjected to an initial conventional microscopic examination when the case ma- terial was first being compiled for this 
study. hn addition to the 365 centrally located le- sions already discussed, the files of our clinic contained a further 370 peripherally located 
lesions recorded during the same period (1950-1980). These 370 were also subjected to an initial conventional microscopic exam- ination, and from this evidence alone it was already apparent that on1y 66 of them could possibly be periodontomas, since the remain- ing 304 were clearly nontumorous. All 370 cases were nevertheless subjected to a further histo1ogical examination, largely because it was thought that the information thus ob- tained might be of some value for differential diagnosis. The tests used were hematoxylin and eosin staining, van Gieson, alcian blue- PAS staining and, in some cases, Goldner's and Giemsa's staining methods (i.e. exact1y the same battery of histological tests as was used for the 107 centrally located lesions remaining after certain clearly irrelevant cases (q.v.) had been eliminated).

A histological examination ofthe material showed that the 370 peripherally located $1 \mathrm{e}$ sions could be divided into three distinct groups, one of which, the smallest, did in fact include all the 66 obviously tumoraus lesions just mentioned. In decreasing order of mag- nitude, the three groups were: (1) reactive hyperplasia of inflammatory origin with or without dystrophic calcium formation; (2) peripheral giant cell granu1oma (otherwise known as giant cell epulis), and (3) tumorous hard lesions characterized by genuine hard tissue formation.

(1) A total of $153(40.3 \%)$ ofthe 370 cases

were assigned to the first group, reactive hy- perplasia of inflammatory origin with or without dystrophic calcification. $106(69.3 \%)$ of the patients were fema1e and 47 $(30.7 \%)$ were male. In 16 of the cases, the original data does not indicate whether the lesion was located in the maxilla or the mandible. Ofthe 137 cases where this information is given, $74(54 \%)$ occurred in the maxilla and 63 (46\%) 
- were localized in the mandible. The histolog- ical characteristics were as follows: many of the lesions were exulcerated and showed edema. The stroma consisted of granulation tissue with a high capillary content, inter- spersed with dense, inflammatory infiltra- tions of lymphocytes, plasma cells and neu- trophilic leukocytes. The clinical examina- tions made at the time generally described the lesions as pathological processes located in the gingiva and characterized by moderate bleeding, and this entirely corresponds to the histological features mentioned.

(2) The second group, peripheral giant cell

granulorna, contained a total of $151(40 \%)$ of the cases. In 6 of these 151 cases there is no indication as to the sex of the patients con-cerned. Of the rernaining 145 cases, $102(70.3 \%)$ occurred in fernale patients, while rna1es were affected in only 43 $(29.7 \%)$ ofthe cases. In 25 of the cases, no indication of the location ofthe lesion is gi ven. Ofthe remaining

126 cases, $79(62.7 \%)$ occurred in the maxilla,

while only $47(37.3 \%)$ were localized in the rnandible. The average age ofthe 151 patients concerned was 49 years. The predominant his- tological feature was the presence of foci of rnultinucleated giant cells. Hemosiderin pig- rnentation was noted and a nurn ber ofhemor- rhages were also observed, sorne ofwhich had clearly occurred shortly before the biopsy had been taken. There was also some evidence of discrete, peripheral bone formation.

(3) The third group, turnorous lesions fea-

turing genuine bone and/or cerneuturn formation, contained 66 cases, and thus accounts for $17.8 \%$ ofthe 370 cases exarnined. A thorough examination of the available clinical, radio- logical and histological data pertaining to these 66 peripherally located ossifying lesions clearly shows thern to be identical to the 15 centrally located periodontomas described 
- earlier. All 81 are histologically identical and quite obviously benign, a feature which distin-guishes thern frorn the 26 cases of desrno- osteoblastorna described in the previous sec- tion ofthis chapter. These 66 benign ossifying lesions can therefore be regarded as periodon-

tornas which differ from the 15 centrally located cases described earlier only by virtue ofthe fact that they occur in a different part of the periodontal tissue. It is therefore proposed that they be termed 'peripheral periodonto- ma', to distinguish them from the 'central periodontorna' already described.

Once it becarne evident that the possibil- ity of periodontornas occurring in the gingiva would have to be investigated, the 1 iterature was reviewed in an atternpt to find reports of histologically cornparable lesions which were peripherally located. It seerns only fitting to conclude this chapter with a sumrnary of ear- lier findings.

\section{Eden [1939] writes: 'The histological}

structure of the fibro-osseous epulis is essen- tially similar to that of the central fibroma, and calcium concretions and spicules ofbone are found in the more cellular areas offibrous tissue. The surface, however, is not covered by a shell of periosteal bone, but lies directly under the mucous membrane ofthe gum, and deep branching processes of squamous epi- thelium pass into its stroma. It lies on the surface of the alveolus and around the tooth roots, and the fibrous tissue blends impercep- tibly with the adjacent periosteum.'

\section{Herzog [1944] describes peripherally lo-}

cated lesions of this type as follows: 'Fibro- matous epulides, which are characterised by the !arge numbers of foci of hyalinised cal- cifying connective tissue they contain, are genetically related to the periodontium and, in particular to the process by which cerneu- turn is forrned. When calcified osteoid for- 
mations occur in isolation and do not appear to produce genuine bone, they are in fact the product of these fibromatous epulides. These "cementicles" can however also occur con- comitantly with bone formations in tumours which are predominantly fibroosteomatous. It is possible that there is a genetic relation- ship between these tumours and the peri- odontium as well, since the periodontium produces cementum with a bone-like struc- ture in the area ofthe tooth roots and since it is also one of the tissues involved in the con- struction ofthe osseous wall ofthe alveolus.' A number of studies oflesions of this type have since been published, though the terminology used varies from author to author. Stafne [1951] speaks of 'peripheral fibromas containing cementum-like substance', whi1e Bruce [1953] prefers to describe these lesions as 'peripheral fibroma of the gingiva with osteogenesis'. Buckman [1958] uses the term

'peripheral odontogenic fibroma with cementogenesis'. Bhaskar and Jacoway [1966] have opted for 'peripheral fibroma with calcifica- tion', Lee [1968] terms them 'fibrous epulis with woven bone formation' and Andersen et al. [1973] have chosen 'calcifying fibroblastic granuloma'.

Eversole and Rovin [1972] give details of a histological examination the authors made of 279 cases of 'reactive lesions of the gingiva'. They subdivided these into three groups 'pyo- genic granuloma/gingival fibromatoid le- sions', 'peripheral giant cell granuloma' and

'peripheral ossifying fibroma'. Their state- ment that clinical and histopathological fea- tures invite speculation that all three lesions represent varied histological responses to irri- tation suggests that they do not regard any of these lesions as 
tumorous. The last group they describe, 'peripheral ossifying fibroma', con- tains a total of 50 cases. They observed two 
distinct histological patterns within this group. They describe the first as being characterized by dense fibrocellular proliferation and add that the quantity of calcified material varied within the specimens and even within the same section. The second type was less frequently encountered and was characterized by deposits of calcified osseous lamellae and trabeculae with circumferential osteoid. Here the stroma varied from dense fibrocellular to predominantly fibrous, with cell nuclei being less densely packed together. The maxil- la:mandible ratio was nearly equal, females outnumbered males by $4.3: 1$ and the average age ofthe patients in the entire group was 25.5 years. The authors point out that one reason why the lesion occurs less frequently in older patients is probably that, as teeth are progres- sively lost, less periodontalligament remains to 'react to irritation with its possible develop- ment of peripheral ossifying fibroma'.

The lesions which have been described in this chapter as trabecular desmoosteoblasto- ma, psammous desmo-osteoblastoma, central periodontoma and peripheral periodontoma are new both in the sense that they have not been described in this way in the literature before and that acceptance of their existence implies a recognition that existing classifica- tions may have tobe revised. The implications of both these considerations are such that it would clearly be highly inappropriate for the existence of these entities to be postulated without ample case material being available to substantiate it. Such material is available in sufficient quantities in the files of our clinic and it will be presented in detail in the next chapter. At the time ofwriting it was thought that the presentation would be clearer if the theoretical arguments presented in this chap- ter were kept separate from the purely practical case material presented in the next. 